\title{
A 5' UTR G-quadruplex controls localisation and translation of a potassium leak channel mRNA
}

Connor J. Maltby ${ }^{1}$, James P. R. Schofield ${ }^{1}$, Steven D. Houghton ${ }^{1}$, Ita O'Kelly ${ }^{2,3}$, Mariana Vargas-Caballero ${ }^{1}$, Katrin Deinhardt ${ }^{1}$, Mark J. Coldwell ${ }^{1, *}$

${ }^{1}$ School of Biological Sciences, University of Southampton, Southampton, Hampshire, SO17 1BJ, UK. ${ }^{2}$ Centre for Human Development, Stem Cells and Regeneration, University of Southampton, Southampton, Hampshire, SO17 1BJ, UK. ${ }^{3}$ Immunocore Limited, Milton, Abingdon, OX14 4RY, UK.

*To whom correspondence should be addressed. Tel: (+44) 2380594 342; Email: m.coldwell@soton.ac.uk

Present Address: Mark J. Coldwell, School of Biological Sciences, University of Southampton, Southampton, Hampshire, SO17 1BJ, UK

\section{ABSTRACT}

RNA G-quadruplexes (G4s) are non-canonical secondary structures that have been proposed to function as regulators of post-transcriptional mRNA localisation and translation. G4s within 3' UTRs of some neuronal mRNAs are known to control their distal localisation and local translation, contributing to the distinct local proteomes that facilitate the synaptic remodelling attributed to normal cellular function. In this study, we characterise the G4 formation of a (GGN) ${ }_{13}$ repeat found within the 5' UTR of KCNK9 mRNA, encoding the potassium 2-pore domain leak channel Task3. Using circular dichroism, we show that this $(G G N)_{13}$ repeat forms a parallel $G 4$ that exhibits the stereotypical potassium specificity of a G4, remaining thermostable under physiological ionic conditions. The G4 is inhibitory to translation of Task3, which can be overcome through the activity of the G4-specific helicase DHX36, consequently increasing $\mathrm{K}^{+}$leak currents and decreasing resting membrane potentials in HEK293 cells. Additionally, we observe that this $\mathrm{G} 4$ is fundamental to ensuring the delivery of Task3 mRNA to distal primary cortical neurites. It has previously been shown that abnormal Task3 expression correlates with neuronal dysfunction, we therefore posit that this $\mathrm{G} 4$ is required for regulated local expression of Task3 leak channels that maintain $\mathrm{K}^{+}$leak currents within neurons. 


\section{INTRODUCTION}

DNA and RNA can adopt many secondary structures that have important roles in dictating cellular processes (1). G-quadruplexes (G4s) form in portions of guanine-rich DNA and RNA, and are amongst the most stable of nucleic acid secondary structures (2). G4s are more stable in RNA than DNA and can exist as mono- or multi-stranded structures (3). G4s compose of stacks of guanine tetrads that stabilise via non-canonical Hoogsteen hydrogen bonding, as opposed to the canonical Watson-Crick bonding observed in duplex DNA/RNA (Figure 1A). Stacked G-tetrads are stabilised through interactions with monovalent cations (4), where $\mathrm{K}^{+}$elicits the greatest stabilisation whereas $\mathrm{Li}^{+}$is unable to stabilise $\mathrm{G} 4$ formation due to constraints in ionic radii within the $\mathrm{G} 4$ central pore $(5,6)$.

G4s are enriched within regulatory elements of both genomic DNA and mRNAs $(7,8)$, clustering at telomeres (9), promoter regions and transcription start sites (10-12) of genomic DNA, as well as splice sites (13) and untranslated regions of mRNAs (14-16). G4s in mRNAs are thought to be of particular importance in the regulation of gene expression, with G4s within the 5' untranslated region (UTR) of mRNAs able to inhibit translation by impeding scanning of the $40 \mathrm{~S}$ ribosomal subunit, or promoting translation through non-canonical ribosomal interactions with internal ribosomal entry sites (IRES) (17). Similarly, G4s within 3' UTRs can impede translation through association with regulatory proteins (18), or indirectly through miRNA recruitment (19) as well as regulating polyadenylation (20) and subcellular localisation of mRNAs $(21,22)$.

Local translation is of particular importance within highly polarised cells, such as within neurons where singular cortical axons can project contra-laterally across the width of the brain. As such, both protein and mRNA transport to these distal sites of neurons is critical to neuronal homeostatic functions (23). Recently, nearly 2000 actively translating mRNAs were identified within the axon through an axonspecific translating ribosome affinity purification (TRAP) approach $(24,25)$. Similarly, identification of translating polyribosomes and over 2500 distinct mRNA transcripts through deep-sequencing within the hippocampal neuropil $(26,27)$ further suggests that neurons have a dependency on the local translation of mRNAs in distal neurite compartments $(23,28)$.

Disruption of G4 homeostasis has been implicated in several neurodevelopmental and degenerative diseases. A G4-forming (CGG) n repeat expansion within mutant forms of the FMR1 gene locus induces aberrant expression of the G4 binding protein FMRP which leads to the neurodevelopmental Fragile-X syndrome (FXS), or the neurodegenerative Fragile-X tremor and ataxia syndrome (FXTAS) (29). Similarly, the G4-forming hexanucleotide $($ GGGGCC) $n$ repeat expansion within the spliced intron 1 of C9Orf72 causes the most common form of inherited amyotrophic lateral sclerosis (ALS), and/or frontotemporal dementia (FTD), through RNA toxicity and repeat-associated non-AUG (RAN) translation producing toxic dipeptide-repeat species (30). As such, the importance of G4s during development and maintenance of synaptic connections through regulated mRNA localisation, as well as their role during neuronal dysfunction and neurodegeneration $(29,31,32)$ is of particular interest.

The TWIK-related acid-sensitive $\mathrm{K}^{+}$channel (Task3, also known as KCNK9 and K2P9.1) is a potassium two-pore domain (K2P) leak channel responsible for regulating the resting membrane potentials of various cell types (33). Task3 is enriched in brain regions associated with high rates of neuronal firing such as the hippocampus and cerebellum (34), and is required during processes such as synaptic plasticity. Task3 loss of function leads to the maternally-imprinted intellectual disability disorder BirkBarel mental retardation (35), and perturbations in Task3 expression lead to changes in resting membrane potentials and neuronal action potential kinetics and recovery (34), suggesting that tight regulation of expression is essential. In this study, we analyse a novel (GGN) 13 repeat in the capproximal region of the 5' UTR of Task3 mRNA (Figure 1B) that folds into a parallel G4 structure responsible for the regulation of distal Task3 mRNA localisation and translational regulation required for the maintenance of normal cellular physiology. 


\section{MATERIAL AND METHODS}

\section{$\underline{\text { Materials }}$}

Primary antibodies used in this study were anti-FLAG M2 (Merck, F1804), anti- $\alpha$-Actin (Sigma, AC-40), anti-Task3 (Merck, K0514), anti-DHX36 (Proteintech, 13159), anti- $\alpha$-Tubulin (Proteintech, 66031), antiLamin (Cell Signalling Technology, 2032). Secondary antibodies used were conjugated to Alexa Fluor® fluorophores (Invitrogen) or IRDyes (LI-COR Biosciences). The plasmids used were cloned from human brain cDNA (Agilent 540005-41) into C-terminal pcDNA3.1-3F/eGFP vectors as previously described (36). Primers were obtained from Sigma, sequences of which are outlined in Figure S5.

Stellaris $®$ RNA FISH probes were obtained from LGC Biosearch Tech. Anti-Task3 mouse RNA FISH probes were designed using the Stellaris ${ }^{\circledR}$ online web tool (see data availability) and conjugated to Quasar $\AA 570 \mathrm{~nm}$ fluorophores. Anti-eGFP RNA FISH probes were pre-designed from Stellaris $\circledast$ and conjugated to Cal Fluor ${ }^{\circledR}$ Red $590 \mathrm{~nm}$ fluorophores.

\section{Circular Dichroism Spectroscopy}

Oligonucleotides were dissolved in nuclease-free $\mathrm{H}_{2} \mathrm{O}$ to a concentration of $1 \mathrm{mM}$ stock solution and diluted to an experimental concentration of $10 \mu \mathrm{M}$, estimated through $\mathrm{OD}_{260}$ absorption, in buffer containing potassium or sodium phosphate and potassium/lithium chloride salt to the desired free $\left[\mathrm{K}^{+} / \mathrm{Li}^{+}\right]$. The oligonucleotide preparations were then folded by heating to $95^{\circ} \mathrm{C}$ for 10 mins and cooled at a rate of $0.5^{\circ} \mathrm{C} / \mathrm{min}$ to room temperature (RT).

CD spectra were recorded using a Jasco J-720 spectropolarimeter equipped with a Jasco PS-450 xenon lamp and a Grant LTD6G temperature-controlled cell holder. Quartz cuvettes of $1 \mathrm{~mm}$ path length were used and scans were recorded at a scan speed of $50 \mathrm{~nm} / \mathrm{min}$ with response time of $2 \mathrm{~s}$. The wavelength of scans was recorded between $320-200 \mathrm{~nm}$, with $0.5 \mathrm{~nm}$ resolution and sensitivity of 20 $\mathrm{m}^{\circ}$. The average of 5 spectral scans was taken for each sample followed by baseline buffer correction. All scans were conducted at $25^{\circ} \mathrm{C}$ except where temperature is the designated independent variable. The data were normalised to molar ellipticity using the equation: $[\theta]=(100 \times \theta) /(\mathrm{c} \times \mathrm{I})$, where $c=$ molar concentration and $\mathrm{I}=$ pathlength in $\mathrm{cm}$.

Temperature controlled experiments were achieved through water-conductive heating of the cell holder. Temperatures were increased from $20^{\circ} \mathrm{C}$ to $95^{\circ} \mathrm{C}$ at $5{ }^{\circ} \mathrm{C}$ increments, allowing 5 minutes stabilisation at each temperature before spectra were obtained. Samples were overlaid with mineral oil to prevent evaporation.

\section{Cell Culture}

HEK293 cells were maintained in DMEM (Dulbecco's Modified Eagle's Medium) media (Gibco) with $10 \%$ FBS supplement (Gibco) and incubated at $37{ }^{\circ} \mathrm{C}$ and $5 \% \mathrm{CO}_{2}$. Cells were transfected using Genejuice $^{\mathrm{TM}}$ (Novagen) as described (37) and proteins extracted after $48 \mathrm{~h}$.

For tissue collection, C57BI/6 wildtype mice were sacrificed in accordance with the Animals (Scientific Procedures) Act 1986 as approved by the UK Home Office. Primary neurons were prepared in Dulbecco's PBS (DPBS, Life Technologies) from cortices of E15-E18 mice. Neurons were dissociated and maintained in complete NBM (Neurobasal medium with $2 \%(\mathrm{v} / \mathrm{v}) \mathrm{B} 27,0.5 \mathrm{mM}$ Glutamax) as previously described (38). The number of cells was determined and plated prior to transfection. For immunocytochemistry/RNA FISH, cells were transfected on day in vitro (DIV) 7 with Lipofectamine 2000 as described (39). The lipoplex mixture was added to the cells and incubated at $37^{\circ} \mathrm{C}$ for $40 \mathrm{~min}$. Subsequently, the lipoplex-containing medium was removed from the wells and replaced with conditioned medium, and the cells were returned to $37^{\circ} \mathrm{C}$. For bicuculline treatment, the cells were treated with $50 \mu \mathrm{M}(+)$-bicuculline (Tocris) or $0.1 \%$ DMSO (vehicle treatment) prepared in complete 
NBM. Cells were incubated at $37^{\circ} \mathrm{C}$ for $24,12,6,3,1 \mathrm{~h}$ and 15 mins and then harvested. For glutamate treatment, the cells were treated with $50 \mu \mathrm{M}$ L-glutamic acid, monosodium salt monohydrate (Sigma) dissolved in $\mathrm{ddH}_{2} \mathrm{O}$ prepared in complete NBM conjunction with a media change control. Cells were incubated for 30,60 or $120 \mathrm{~s}$, media changed and then allowed to recover for $1 \mathrm{~h}$ at $37^{\circ} \mathrm{C}$ before being harvested.

For protein/RNA isolation using Corning ${ }^{\circledR}$ Costar $^{\circledR}$ Transwell $^{\circledR}$ inserts (24 mm diameter, 3491), murine embryonic cortical neurons were seeded at the desired density and protein/RNA harvested at DIV7. Axonal preparations were isolated as described (40).

\section{HEK293 Cell Recording}

HEK293 cells were maintained and transfected as above and whole-cell patch clamp was performed after $24 \mathrm{~h}$ transfection. Thick-glass borosilicate glass micropipettes were pulled to a tip resistance of 5$7 \mathrm{mOhm}$ then filled with intracellular recording solution containing: $115 \mathrm{mM}$ potassium gluconate, 10 $\mathrm{mM} \mathrm{KCl}, 10 \mathrm{mM}$ HEPES, $10 \mathrm{mM}$ potassium phosphocreatine, $0.4 \mathrm{mM}$ GTP, $4 \mathrm{mM}$ ATP, and $\mathrm{pH}$ balanced to 7.3 with $\mathrm{KOH}$. Osmolarity of $\sim 280 \mathrm{mOsm}$. Cells were perfused with artificial cerebrospinal fluid (ACSF) kept at $37^{\circ} \mathrm{C}$ throughout recording. ACSF contained: $126 \mathrm{mM} \mathrm{NaCl}, 2 \mathrm{mM} \mathrm{CaCl} 2,10 \mathrm{mM}$ glucose, $2 \mathrm{mM} \mathrm{MgSO}_{4} .7 \mathrm{H}_{2} \mathrm{O}, 3 \mathrm{mM} \mathrm{KCl}, 1.25 \mathrm{mM} \mathrm{NaH}_{2} \mathrm{PO} 4.2 \mathrm{H}_{2} \mathrm{O}$ and $26.4 \mathrm{mM} \mathrm{NaHCO}_{3}$, bubbled with carbogen gas $\left(95 \% \mathrm{O}_{2}, 5 \% \mathrm{CO}_{2}\right)$. Osmolarity of $\sim 300 \mathrm{mOsm}$. The membrane potential was measured using a Multiclamp 700B (Molecular Devices) in current clamp (bridge) mode. Membrane potential was corrected for liquid junction potential of $-12.5 \mathrm{mV}$ which was measured directly (41).

\section{Western Blotting}

Proteins were extracted in Radioimmunoprecipitation assay (RIPA) buffer (150 mM NaCl, $1 \%$ (v/v) NP40, $1 \%(\mathrm{w} / \mathrm{v})$ DOC, $0.1 \%(\mathrm{v} / \mathrm{v}) \mathrm{SDS}, 50 \mathrm{mM}$ Tris HCL pH 7.6, $1 \mathrm{mM}$ EDTA, $1 \mathrm{mM}$ EGTA, 1X Halt protease and phosphatase inhibitor cocktail (Thermo)) as previously described (42). Protein lysates were prepared and blotted following standard procedures, and images were captured using the Odyssey IR Imaging System (LI-COR Biosciences). Image Studio Scanner software was used to obtain the image, and Image Studio Lite software was used to quantify the intensities of the bands.

\section{RT-PCR and RT-qPCR}

RNA was extracted using the NucleoSpin ${ }^{\circledR}$ RNA extraction kit (Machery Nagel) according to manufacturer's instructions. RNA was reverse transcribed to cDNA using the qScript cDNA Supermix (QuantaBio) according to manufacturer's instructions. Endpoint PCRs were carried out using Readymix ${ }^{\mathrm{TM}}$ Taq PCR Reaction Mix (Sigma) with primers obtained from Sigma (see materials and Figure S5). Quantitative PCR (qPCR) amplification was performed using SYBR® Select Master Mix (Life Technologies) and an Eco qPCR System (Illumina) using the following conditions: initial denaturation $95^{\circ} \mathrm{C}$ for $5 \mathrm{~min}, 40$ cycles of denaturation at $95^{\circ} \mathrm{C}$ for $10 \mathrm{~s}$, and data collection at $60{ }^{\circ} \mathrm{C}$ for $1 \mathrm{~min}$. All reactions were performed with two technical replicates. The expression level was normalised to the level of the reference genes stated and quantified using the $\Delta \Delta \mathrm{Ct}$ method.

\section{RNA Fluorescence in Situ Hybridisation (FISH)}

At the desired timepoint, cells were fixed in $4 \%(\mathrm{v} / \mathrm{v})$ paraformaldehyde and permeabilised using DPBS containing $0.1 \%(\mathrm{v} / \mathrm{v})$ Triton X-100 and washed with Stellaris ${ }^{\circledR}$ Wash Buffer A (with $10 \%(\mathrm{v} / \mathrm{v})$ formamide). Fluorescent probes were then diluted into hybridisation buffer (30 $\mathrm{mM}$ saline sodium citrate buffer, $0.2 \%(\mathrm{w} / \mathrm{v}) \mathrm{BSA}, 10 \%(\mathrm{w} / \mathrm{v})$ dextran sulphate, $50 \%(\mathrm{w} / \mathrm{v})$ formamide) to a concentration of 125 $\mathrm{nM}$ and $100 \mu \mathrm{l}$ was placed onto coverslips. Coverslips were incubated in a light-protected humidified chamber at $37^{\circ} \mathrm{C}$ for $16 \mathrm{~h}$. Coverslips were transferred to $1 \mathrm{ml}$ Stellaris ${ }^{\circledR}$ Wash Buffer A containing 375 $\mathrm{nM}$ Hoechst stain (Sigma) and incubated in a light-protected humidified chamber at $37^{\circ} \mathrm{C}$ for $30 \mathrm{~min}$. Coverslips were then washed in Stellaris ${ }^{\circledR}$ Wash Buffer B and mounted for imaging. The cells were 
bioRxiv preprint doi: https://doi.org/10.1101/797423; this version posted October 10, 2019. The copyright holder for this preprint (which was not certified by peer review) is the author/funder, who has granted bioRxiv a license to display the preprint in perpetuity. It is made available under aCC-BY-NC-ND 4.0 International license.

imaged using a X60/1.42 NA Oil Plan Apo objective on a DeltaVision Elite system (GE Life Sciences) with an SSI 7-band light-emitting diode for illumination and a monochrome sCMOS camera using SoftWoRks software (version 6). 4',6-diamidino-2-phenylindole, FITC, TRITC, Cy-5, and DIC channels were used. The images were analysed using the Fiji image processing package $(\mathrm{NIH})$. 


\section{RESULTS}

\section{In silico bioinformatic tools predict G-quadruplex formation for the Task3 (GGN) 13 repeat}

5' Rapid amplification of cDNA ends (5' RACE) sequencing of full-length Task3 5' UTR from human brain mRNA revealed a 71 nucleotide (nt) 5' UTR N-terminal extension, which when sequenced was found to contain a (GGN) 13 repeat $11 \mathrm{nt}$ downstream of the $\mathrm{m}^{7} \mathrm{G} 5^{\prime}$-cap (Figure 1B). GGN repeats can form G4es as well as intermittently bulged duplex secondary structures within mRNA (43). To predict the structures potentially formed by this (GGN) 13 repeat, we used the in silico $G 4$ prediction tools, QGRS mapper (44) and the cG/cC scoring system (45). QGRS mapper designates a score based on the G4 consensus sequence of $\left[\mathrm{G}_{2+} \mathrm{N}_{1-7}\right]_{4+}$, which can be used in comparison to scores of known $\mathrm{G} 4$ forming sequences, such as NRAS G4 (Figure 1C). In contrast, the $\mathrm{cG} / \mathrm{cC}$ scoring system designates a minimum score of 2.05 for $\mathrm{G} 4$ formation. Both methods suggest Task3 (GGN) 13 is predicted to form a G4 structure when constrained as a (GGN) $)_{13}$ repeat (21 for a singular G4 or 59 for 3 tandem G4s) and when in the context of the extended 5' UTR sequences (Figure 1C). We compared scores for Task3 (GGN) ${ }_{13}$ to the well characterised NRAS 5' UTR G4 structure (14), a duplex forming control (predicted through RNAfold), and Task3 (GGN) ${ }_{13} / \mathrm{NRAS}$ G/C matched complementary sequence controls. Task3 (GGN) ${ }_{13}$ and NRAS wild-type (WT) G4 were both predicted to form G4s, whilst the remaining controls were not.

\section{$\underline{\text { Task3 (GGN) }{ }_{13} \text { forms a parallel G-quadruplex at physiological }\left[\mathrm{K}^{+}\right]}$}

To address the sequence prediction scores from Figure 1C, we used circular dichroism spectroscopy $(\mathrm{CD})$ to interrogate the structural conformation of the Task3 5' UTR (GGN) ${ }_{13}$ repeat using DNA oligonucleotides of various sequences of interest (Figure 1C). DNA oligonucleotides were used in place of RNA due to availability and increased experimental versatility. Given that DNA analogues of parallel RNA G4s show the same G4 forming ability and CD traces, this posed no issues when investigating Task3 (GGN) ${ }_{13}$ G4 formation (46). At a physiological concentration of $150 \mathrm{mM} \mathrm{K}^{+}$, Task3 wild-type (WT) $(G G N)_{13}$ forms a parallel G4, exhibiting the spectral maxima $\left(\lambda_{\max }\right)$ of $210 \mathrm{~nm}$ and $261 \mathrm{~nm}$ (Figure 1D) previously reported for and consistent with parallel $\mathrm{G} 4$ formation $(46,47)$, which was also observed for NRAS WT G4 (Figure 1E).

To further test G4 formation for Task3 (GGN) 13 $_{3}$, we compared the CD spectra of the WT G4 forming sequence to the complementary $(\mathrm{CCN})_{13}$ sequence to prevent $\mathrm{G} 4$ formation without disrupting the ability for any potential duplex formation through canonical Watson-Crick base pairing. At $150 \mathrm{mM} \mathrm{K}^{+}$, the Task3 complementary $(\mathrm{CCN})_{13}$ sequence exhibits a $\lambda_{\max }$ at $\sim 280 \mathrm{~nm}$ and $\lambda_{\min }$ at $210 \mathrm{~nm}$ and $250 \mathrm{~nm}$ (Figure 1D), typical of a B-form duplex (48), suggesting the formation of a different, non-G4 structural conformation when compared to Task3 WT $(G G N)_{13}$. From this, it is likely the presence of doublet guanine-tracts that is contributing to the structural conformation observed for Task3 WT (GGN) ${ }_{13}$, and not Watson-Crick base pairing due to the distinct non-B conformation. When complementing the NRAS G4 sequence, a loss of any defining $\lambda_{\max / \min }$ is observed, suggesting that no structure is likely to be forming (Figure 1E).

Hoogsteen hydrogen bonding is fundamental to $\mathrm{G} 4$ formation. We therefore sought to inhibit G4 formation through pre-incubation of the oligonucleotides with $1 \%$ dimethylsulphate (DMS), inducing methylation at the N7 position of guanine and preventing the Hoogsteen hydrogen bonding between N7 and the C2 amino group of neighbouring guanines (49) (Figure S1A). Upon methylation, both Task3 WT (GGN) 13 and NRAS WT G4 exhibited reduced molar ellipticity ([$\theta])$ at the $\lambda_{\max }$ of $210 \mathrm{~nm}$ and 261 $\mathrm{nm}$ (Figure $1 \mathrm{~F}$ and S1B respectively), indicating reduced $\mathrm{G} 4$ formation. However, the complementary base sequences and duplex controls showed stabilisation and increase in molar ellipticity at their respective $\lambda_{\max }$ that do not correspond to $\mathrm{G} 4$ formation (Figure S1 C, D and E). These data therefore suggest a dependency of Hoogsteen guanine-guanine hydrogen bonding on the structural conformations observed at $150 \mathrm{mM} \mathrm{K}^{+}$for Task3 WT (GGN) 13 and NRAS WT G4. Further, we observed that Task3 WT (GGN) ${ }_{13}$ G4 formation was independent of oligonucleotide concentration through no 
change in CD signature of between 1-50 $\mu \mathrm{M}$ oligonucleotides, indicative of an intramolecular $\mathrm{G} 4$ as opposed to a multi-strand association dependent on oligonucleotide concentration (data not shown). The G4 structure was maintained when in the presence of the $11 \mathrm{nt}$ upstream and $10 \mathrm{nt}$ downstream of the Task3 5' UTR (GGN) ${ }_{13}$ repeat, and so was therefore also maintained in a wider sequence context (Figure S2A).

Unlike duplex structures, G4 formation is dependent on the availability of monovalent cations to stabilise the central electronegative pore (4) (Figure 1A). To test the ionic dependency of Task3 (GGN)13, we compared $\mathrm{G} 4$ formation under different ionic conditions, either $\mathrm{K}^{+}$to permit $\mathrm{G} 4$ formation or $\mathrm{Li}^{+}$to inhibit G4 formation. At $150 \mathrm{mM} \mathrm{K}^{+}$, Task3 (GGN) 13 forms a parallel G4, exhibiting the CD $\lambda_{\max }$ of 210 and 261 $\mathrm{nm}$ (Figure 1G), whilst the duplex control exhibits a $\lambda_{\min }$ of 210 and $250 \mathrm{~nm}$ and $\lambda_{\max }$ of $270-280 \mathrm{~nm}$, typical of a B-form duplex (Figure S2B). For Task3 WT (GGN) ${ }_{13}$ we observe a complete shift in spectral shape when folded in the presence of $150 \mathrm{mM} \mathrm{Li}^{+}$(Figure 1G), exhibiting a similar trace to that observed for the duplex control, indicating an absence of $\mathrm{G} 4$ formation in $\mathrm{Li}^{+}$and a strong dependency on $\mathrm{K}^{+}$ availability for Task3 G4 formation. As expected, the duplex sequence showed no ionic sensitivity, and its $\mathrm{CD}$ trace was maintained fully when shifting from $\mathrm{K}^{+}$to $\mathrm{Li}^{+}$(Figure S2B). These results suggest that in the absence of $\mathrm{K}^{+}$and presence of $\mathrm{Li}^{+}$, alternative molecular bonding is favoured for Task3 (GGN) ${ }_{13}$ instead of the guanine-guanine Hoogsteen bonding critical for $\mathrm{G} 4$ formation, a characteristic typical of G4 structures.

\section{Task3 (GGN) ${ }_{13}$ G-quadruplex formation is $\mathrm{K}^{+}$dependent}

In order to further characterise the $\mathrm{K}^{+}$-dependency of $\mathrm{G} 4$ formation for Task3 $(\mathrm{GGN})_{13}$, we analysed the $\mathrm{CD}$ spectra in the presence of different $\mathrm{K}^{+}$concentrations from 5-150 $\mathrm{mM} \mathrm{K}^{+}$. As before, we observe 2 distinct structural conformations at low vs high $\mathrm{K}^{+}$concentrations, with spectra indicative of $\mathrm{G} 4$ formation only observed at $50 \mathrm{mM} \mathrm{K}^{+}$and above. We observe an increase of approximately 10-fold in molar ellipticity at 210 and $261 \mathrm{~nm}$ between $50-150 \mathrm{mM} \mathrm{K}^{+}$(Figure 2A and B). These data suggest a strong dependence on higher physiological $\mathrm{K}^{+}$concentrations for Task3 $\mathrm{G} 4$ formation, and also the potential for Task3 (GGN) $)_{13}$ to form alternative structures, such as a duplex (Figure $2 \mathrm{C}$ ) at low $\left[\mathrm{K}^{+}\right]$.

Conformational shifts from duplexes to G4es have been observed in several instances upon changes in ionic concentrations $(50,51)$. Here however, we observe a conformational shift only when the ionic composition was discretely changed before folding of the oligonucleotides, with no change in Task3 spectra when $\mathrm{Li}^{+}$was added to oligonucleotides that had been pre-folded in $150 \mathrm{mM} \mathrm{K}^{+}$(Figure S2C), or when more $\mathrm{K}^{+}$was added to oligonucleotides pre-folded in $5 \mathrm{mM} \mathrm{K}^{+}$(Figure S2D). This further indicates that in the presence of low concentrations of $\mathrm{K}^{+}$, Task3 WT (GGN) $)_{13}$ is not single stranded as increasing $\mathrm{K}^{+}$thereafter does not induce $\mathrm{G} 4$ formation and the presence of increased $\mathrm{K}^{+}$is unable to overcome the ordered structure formed at low $\left[\mathrm{K}^{+}\right]$.

\section{Task3 5' UTR WT G-quadruplex is thermostable under physiological conditions}

G4es are highly thermostable under physiological ionic conditions (3), and so we characterised the thermostability of the Task3 (GGN) ${ }_{13} \mathrm{G} 4$ in order to determine whether the $\mathrm{G} 4$ melting temperature was above physiological temperature. We performed a CD melt assay using $10 \mu \mathrm{M}$ experimental oligonucleotides that were folded in $150 \mathrm{mM} \mathrm{K}^{+}$and analysed within a Peltier cooled cell holder from 20-100 ${ }^{\circ} \mathrm{C}$, with spectra obtained at $5^{\circ} \mathrm{C}$ intervals.

Task3 (GGN) ${ }_{13}$ G4 exhibited a highly stable thermal profile, with no reduction in molar ellipticity at the $\lambda_{\max }$ until $75-80^{\circ} \mathrm{C}$ (Figure 2D and E). From these data it is evident that the $\mathrm{G} 4$ is thermostable under physiological $\mathrm{K}^{+}$, with an estimated melting temperature of between $75-80{ }^{\circ} \mathrm{C}$ from the first derivative calculation of the melt curve for Task3 WT (GGN) ${ }_{13}$ (Figure 2F). These data suggest that if $\mathrm{G} 4$ formation is maintained in the presence of $150 \mathrm{mM} \mathrm{K}^{+}$in vivo, the Task3 (GGN) ${ }_{13} \mathrm{G} 4$ would remain folded at physiological temperature and could contribute to post-transcriptional regulation of the expression of Task3 channels. 


\section{Task3 5' UTR G-quadruplex inhibits translation of Task3-FLAG reporter constructs}

To study the influence of the 5' UTR (GGN) ${ }_{13}$ G4 on the translation efficiency of Task3, we generated reporter constructs possessing WT or mutated regions within the 5' UTR G4 region (Figure 3A) that all produce identical 3x FLAG tagged peptides termed Task3 ${ }^{\mathrm{M} 1}-3 \mathrm{~F}$ (Figure 3B). The product of translation consisted only of the $\mathrm{N}$-terminal cytoplasmic and first transmembrane domains in order to avoid formation of functional Task3 $\mathrm{K}^{+}$channels that would alter intracellular $\mathrm{K}^{+}$concentration. Upstream of the coding sequence, the constructs differ only in the G-rich (GGN) 13 region between positions -120 and -81 , with the wild-type containing the $131 \mathrm{nt} 5$ ' UTR, the complementary control containing a $(\mathrm{CCN})_{13}$ repeat mutation within the $39 \mathrm{nt} \mathrm{G} 4$ region, and the $\Delta \mathrm{G} 4$ containing complete deletion of this $39 \mathrm{nt}$ portion, whilst maintaining the rest of the $95 \mathrm{nt} 5^{\prime}$ UTR (Figure $3 \mathrm{~A}$ ).

HEK293 cells were transfected with the FLAG-tagged reporter constructs and protein lysates were analysed through Western blotting 48 hours post-transfection (Figure $3 \mathrm{C}$ ). Task3 ${ }^{\mathrm{M} 1}-3 \mathrm{~F}$ expression was normalised to $\alpha$-actin and quantified (Figure 3D), and a significant degree of expressional control was elicited in the presence of the 5' UTR G4. We observed an increase in expression of Task3 ${ }^{\mathrm{M} 1}$-3F by $\sim 6-$ fold upon deletion of the $(G G N)_{13}$ repeat in the $\Delta G 4$ sample, thus suggesting it acts as a key regulatory mechanism of controlling rates of Task3 translation. Interestingly, not all mutants showed the same degree of expression increase, with the complementary $(\mathrm{CCN})_{13}$ repeat eliciting only a partial relief in translation repression compared to the WT G4. This further suggests the formation of an alternate secondary structure such as a duplex or intercalated motif (i-motif), as suggested in Figure 1D. To confirm that the observed increase in Task3 ${ }^{\mathrm{M} 1}-3 \mathrm{~F}$ expression was due to G4-induced translational repression as opposed to transcriptional repression, we quantified levels of Task3 ${ }^{\mathrm{M} 1}-3 \mathrm{~F}$ mRNA via qPCR (Figure 3E). When normalised to the endogenous HEK293 beta-2-microglobulin ( $\beta 2 \mathrm{M})$, Task3 ${ }^{\mathrm{M} 1}$ 3F mRNA levels remained consistent for all constructs, indicating no changes in levels of transcription. Similarly, levels of neomycin phosphotransferase 2 (NPTII) mRNA, an internal vector control gene expressed from the transfected plasmids, were analysed in comparison to endogenous $\beta 2 \mathrm{M}$ mRNA to ensure consistent levels of transfection for each construct (Figure 3E). These data suggest that all constructs possess no significant difference in transfection rate nor levels of Task $3^{\mathrm{M} 1}-3 \mathrm{~F}$ transcription.

The data from Figure 3D and $\mathrm{E}$ allowed for comparison of relative mRNA to protein levels for Task3 ${ }^{\mathrm{M} 1}$ $3 \mathrm{~F}$ to inform us of the translation efficiency for each construct (Figure 3F). These data further suggest that the increase in Task3 ${ }^{\mathrm{M} 1}-3 \mathrm{~F}$ expression upon deletion of the $\mathrm{G} 4(\Delta \mathrm{G} 4)$ is due the loss of the translationally-repressive moiety.

\section{Overexpression of the G-quadruplex helicase DHX36 partially relieves the (GGN) $)_{13}$ G4 translation repression of Task3}

The DEAH-box helicase 36 (DHX36) is a G4 resolving helicase (52). Binding to G4s increases translation, prevents the accumulation of translationally repressed mRNAs (53) and has also been shown to be important in the neurite localisation of certain RNA species (54). We therefore next investigated whether overexpression of DHX36 in HEK293 cells could relieve the G4 mediated translation repression observed for Task3 ${ }^{\mathrm{M} 1} \mathrm{mRNA}$.

HEK293 cells transfected with a FLAG-DHX36 construct (3F-DHX36) drove an average increase in DHX36 expression of between 10-15-fold, from quantification of total vs FLAG-DHX36 (Figure 4A, left). HEK293 cells were subsequently co-transfected with Task3 ${ }^{\mathrm{M} 1}-3 \mathrm{~F}$ WT or mutant $5^{\text {' }}$ UTR constructs and either FLAG-DHX36 (3F-DHX36) or Firefly Luciferase-FLAG (Fluc-3F) as a co-transfection control. Expression for each condition was normalised to the Task3 $\Delta \mathrm{G} 4$ to compare translation efficiencies of G4 vs non-G4 mRNA in the presence of DHX36 or Fluc-3F (Figure 4A, right). When co-expressed with Fluc-3F, Task3 ${ }^{\mathrm{M} 1}-3 \mathrm{~F}$ maintained a similar expression pattern for the three 5' UTR variants as was previously observed in Figure 3C-D. However, upon co-transfection with 3F-DHX36, we observed an increase of $\sim 2$-fold for the proportion of Task3 ${ }^{\mathrm{M} 1}-3 \mathrm{~F}$ WT G4 expression when compared to the $\Delta \mathrm{G} 4$ control in the presence of 3F-DHX36. In contrast, when the 5' UTR (GGN) ${ }_{13}$ sequence was mutated to 
$(\mathrm{CCN})_{13}$, in the presence of $\mathrm{DHX} 36$ we observed no significant change in Task3 ${ }^{\mathrm{M} 1}$-3F expression when compared to the Fluc-3F control. These data indicate DHX36 has preferential activity between samples, confirming that Task3 (GGN) ${ }_{13}$ G4 formation is maintained and that the Task3 Comp is forming an alternate structure to a $\mathrm{G} 4$, that is still mildly repressive to translation.

To investigate whether Task3 mRNA was a target of DHX36 endogenously and within the context of its full-length coding sequence, we analysed the expression of endogenous Task3 upon overexpression of DHX36 (Figure S3A). We observe that upon transfection of 3F-DHX36, endogenous Task3 expression was increased by an average of 1.25 -fold when compared to the Fluc-3F transfection control. This suggests that Task3 (GGN) ${ }_{13}$ G4 formation is maintained in cells for both endogenous and exogenous transcripts, signified by the preferential relief of translation inhibition of the Task3 WT $(\mathrm{GGN})_{13} \mathrm{G} 4$ transcripts from overexpression of the G4-specific helicase DHX36.

\section{Increasing Task3 expression through DHX36 G-quadruplex unwinding decreases the resting membrane potential of HEK293 cells}

Since overexpression of DHX36 leads to an increase in endogenous Task3 expression in HEK293 cells (Figure S3A), we sought to investigate if this overexpression would lead to a Task3 dependent alteration in the membrane potential of HEK293 cells from increased $\mathrm{K}^{+}$leak currents. HEK293 cells display a resting membrane potential of $\sim 40 \mathrm{mV}(55)$. We predicted that an increase in plasma membrane expression of Task $3 \mathrm{~K}^{+}$channels would allow us to detect a negative shift in membrane potential. We measured membrane potentials of HEK293 cells transfected with either Fluc-3F or 3F-DHX36, as carried out in previous experiments. When compared to cells transfected with Fluc-3F, we did not observe a significant decrease in resting membrane potential of cells transfected with 3F-DHX36 ($38.75 \pm 3.14 \mathrm{mV},-41.25 \pm 2.45 \mathrm{mV}, \mathrm{p}=0.15$ ) (Figure S3B). These data however suggest that $\mathrm{DHX} 36$ is unlikely to have a broad spectrum of mRNA targets that would lead to a significant alteration in resting membrane potential, although cells transfected with high concentrations of 3F-DHX36 did show increased cell death (data not shown).

Task3 mRNA abundance is relatively low and our data suggest that the action of DHX36 is likely limited by the amount of available Task3 mRNA for it to resolve. To investigate this, we co-transfected in a fulllength Task3 construct possessing the WT 5' UTR (FL Task3-3F) with either Fluc-3F or 3F-DHX36, in an attempt to increase Task3 mRNA levels and drive a larger decrease in resting membrane potential in the presence of 3F-DHX36 when compared to the Fluc-3F control. Whilst overexpression of DHX36 was able to drive a 1.2-fold increase in endogenous Task3 expression in comparison to FLuc-3F (Figure $\mathrm{S} 3 \mathrm{~A}$ ), an overexpression of both DHX36 and Task3 mRNA was able to further drive an increase in FL Task3-3F expression of 2-fold over endogenous levels (Figure 4B), similar to the level of increase observed for the overexpression of Task ${ }^{\mathrm{M} 1}-3 \mathrm{~F}$ (Figure $3 \mathrm{~A}$ ). This was accompanied by a highly significant decrease in resting membrane potential for FL Task3-3F + 3F-DHX36 compared to FL Task3-3F + Fluc$3 \mathrm{~F}(33.59 \pm 2.4 \mathrm{mV}, 68.41 \pm 4.14 \mathrm{mV}, \mathrm{p}=0.0001)$ (Figure. $4 \mathrm{C})$ suggesting that Task3 channels are incorporated into the plasma membrane, allowing $\mathrm{K}^{+}$permeability of the cell to be increased.

\section{Distal localisation of Task3 mRNA is dependent on presence of the 5' UTR G-quadruplex}

There is increasing evidence that G4s are involved in regulating local translation of neuronal mRNAs through permitting the localisation of mRNA to these distal compartments $(21,56)$. We therefore wanted to investigate whether in addition to regulating translation. The 5' UTR G4 also mediated subcellular localisation of Task3 mRNA. To investigate this, the mutant $5^{\prime}$ UTR Task3 ${ }^{\mathrm{M} 1}$ constructs were used as in previous experiments, but with the FLAG tag substituted for eGFP to provide a longer target sequence for RNA FISH probes, as well as to distinguish between endogenous Task3 mRNA and the experimental G4 exogenous Task $3^{\mathrm{M} 1}$ transcripts. Subcellular localisation of exogenous WT G4 Task3 ${ }^{\mathrm{M} 1}$-eGFP mRNA was initially determined within murine embryonic cortical neurons through simultaneous FISH and immunofluorescence for the respective axonal and dendritic markers, tau and MAP2 (Figure 5A). Exogenous WT G4 Task3 ${ }^{\mathrm{M} 1}$-eGFP mRNA was localised to both axons and dendrites, 
where mRNA respectively co-localised with tau and MAP2. We subsequently sought to identify how mutating the 5' UTR (GGN) ${ }_{13}$ G4 repeat influenced neuronal subcellular localisation of Task3 mRNA to determine whether the Task3 5' UTR G4 was responsible for neurite localisation.

To address this, the mutant constructs were co-transfected into murine embryonic cortical neurons with Fluc-3F to enable the staining of whole individual transfected cells within the dense neuronal network. Cells were fixed and co-hybridised with anti-eGFP mRNA probes and anti-FLAG M2 primary antibody (Figure 5B). Transfected cells possessing neurites $\geq 100 \mu \mathrm{m}$ in length were analysed for the distance that exogenous Task ${ }^{\mathrm{M} 1}$-eGFP mRNA could be detected from the cell body (Figure $5 \mathrm{C}$ ).

The Fluc-3F staining indicates that extensive neurite outgrowth was achieved for embryonic murine cortical cells in culture, however, despite consistent levels of neurite outgrowth in each condition, the distance of Task3 ${ }^{\mathrm{M} 1}$-eGFP mRNA reactivity from the cell body of each neuron varied considerably between each of the 5' UTR G4 region mutants. One-way ANOVA analysis indicates a significant effect of the $G 4$ region manipulation on mRNA distance from the cell body, $F(3,247)=89.01, p<0.0001$. Further post-hoc pairwise comparisons showed that the $\Delta \mathrm{G} 4$ Task $3^{\mathrm{M} 1}$-eGFP mRNA showed no significant difference to the eGFP only control, yielding averages of $14.84 \pm 1.46 \mu \mathrm{m}$ and $17.15 \pm 2.75$ $\mu \mathrm{m}$ respectively ( $\mathrm{ns}, \mathrm{p}=0.99$ ). In contrast, Comp Task3 ${ }^{\mathrm{M} 1}$-eGFP mRNA showed slightly elevated distances for mRNA detection from the cell body in comparison to the eGFP control, with an average of $34.34 \pm 2.26 \mu \mathrm{m}(p=0.02)$. However, WT G4 Task3 ${ }^{\mathrm{M} 1}$-eGFP mRNA showed the greatest distance of detection from the cell body out of all conditions, with an average of $85.23 \pm 4.83 \mu \mathrm{m}(p<0.0001)$. These data suggest that the presence of either the $(\mathrm{GGN})_{13}$ or $(\mathrm{CCN})_{13}$ repeat within the 5 ' UTR was sufficient to drive a significant change in neurite mRNA localisation, with the presence of the $(G G N)_{13}$ G4 forming sequence required for full distal neurite localisation. When comparing within the G4 region mutants, both complementing and deleting the $(G G N)_{13}$ repeat yielded highly significant reductions in distal neurite mRNA localisation when compared to the WT G4, further suggesting that the Task3 WT (GGN) ${ }_{13}$ G4 formation is required for distal Task3 mRNA localisation. Interestingly however, neurite localisation is not completely lost when complementing the (GGN) ${ }_{13}$ repeat as it is when deleting the repeat. As inferred from Figures 1 and 3 , it is likely that the $(C C N)_{13}$ repeat forms an alternative secondary structure such as a duplex/stem-loop or intercalated motif (i-motif) due to the CD spectra and translational repression observed. This could also be influencing subcellular localisation of the transcripts through a distinct mechanism to that of G4 driven localisation, potentially mediated by an alternative family of RNA binding proteins (RBP).

\section{Task3 mRNA is distally localised to neurites in murine embryonic cortical neurons}

With the identification of a parallel G4 structure in the 5' UTR of Task3 mRNA that regulates translational efficiency and localisation of exogenous Task $3^{\mathrm{M} 1} \mathrm{mRNA}$, we finally wanted to identify how endogenous Task3 mRNA is localised within the context of the full-length endogenous transcripts. To investigate subcellular localisation of endogenous Task3 mRNA in cortical neurons, we used RNA FISH probes targeting mouse Task3 mRNA. Wild type murine embryonic cortical cells were cultured in vitro and transfected with eGFP to highlight individual cells within dense neuronal cultures. When tracing neurites from a single eGFP transfected neuron, endogenous Task3 mRNA was observed to be present in both the distal axonal (1) and dendritic (2) projections (Figure 6A).

To confirm the presence of Task3 mRNA and protein in distal axonal projections, cortical cells were cultured in Transwell ${ }^{\circledR}$ inserts (Figure 6B). This allows separation of axonal projections by allowing the growth of a mixed neurite population on the apical membrane face, whilst only an axonal population on the basal membrane face due to constraints in width of the membrane pores (40). RNA and protein extracted from both sides of the Transwell ${ }^{\circledR}$ inserts were analysed through RT-PCR (Figure 6B, left) and Western blotting (Figure 6B, right) for the presence of Task3 and DHX36. The detection of nuclearlocalised lamin protein and histone 1 (H1F0) mRNA in only the whole-cell mixed preparation, as well as the detection of Tau protein and $\beta$-actin mRNA in both axonal and whole-cell preparations confirms 
clean isolation of axon-only samples with no cross-membrane contamination. From this, Task 3 protein and mRNA were also detected in both preparations, confirming the presence of Task3 mRNA and protein in the distal axon. The presence of Task3 mRNA in both axonal and dendritic projections correlates with that observed for exogenous Task $3^{\mathrm{M} 1}$ mRNA, suggesting that the G4-mediated control of exogenous mRNA localisation may too be seen for the endogenous Task3 mRNA. Similarly, the presence of endogenous Task3 mRNA distally from the cell body suggests a potential contribution of local translation to Task3 expression.

\section{Both Task3 mRNA and protein are upregulated in response to neuronal activity}

Neuronal activity plays a key role in regulating the spatiotemporal control of local translation that underpins dynamic plasticity at synapses (57-59). Since Task3 mRNA is localised to distal neurites, we sought to examine the role that neuronal activity may play in Task3 mRNA levels, localisation and protein expression. Neuronal cultures contain a finely balanced network of excitatory and inhibitory neurons, with inhibitory neurons becoming responsive at DIV7 and full maturation of network connections at DIV12-13 (60). As a result of this heterogeneous cell population, different pharmacological approaches can be utilised to elicit neuronal activity, with differing intensities and functional outcomes. Bicuculline is a GABA receptor antagonist that increases neuronal spiking and synaptic protein expression (61), whilst glutamate activates metabotropic and ionotropic receptors including AMPA and NMDA ion channels (62).

We treated wild-type DIV13 murine embryonic cortical neurons with $50 \mu \mathrm{M}$ bicuculline or a DMSO vehicle control over a $24 \mathrm{~h}$ period to induce a low-level increase in basal neuronal spiking through a blockade of inhibitory circuits (Figure 6C, top). Similarly, we also treated DIV13 murine embryonic cortical neurons with $50 \mu \mathrm{M}$ glutamate for $30 \mathrm{~s}, 1$ and 2 mins with a $1 \mathrm{~h}$ recovery period, to induce a short period of intense neuronal activation. RNA was extracted and analysed through RT-qPCR for levels of Task3 mRNA relative to GAPDH (Figure 6C, bottom).

We find that both bicuculline and glutamate are able to induce transcription of Task3 mRNA to differing degrees. Treatment with a DMSO vehicle control induced no change in Task3 mRNA levels, whereas treatment with $50 \mu \mathrm{M}$ bicuculline induced a modest but consistent increase in Task3 mRNA of between 1.5-2-fold over a $24 \mathrm{~h}$ period of stimulation. However, treatment with $50 \mu \mathrm{M}$ glutamate for just $60 \mathrm{~s}$ followed by a $1 \mathrm{~h}$ recovery period was sufficient to elicit a 3-fold increase in Task3 mRNA, and treatment for 120 s elevated Task3 mRNA levels between 7-8-fold.

In addition to upregulation of mRNA transcription within the nucleus, neuronal activity is also a key driver of regulated local protein synthesis in distal neuronal compartments (63). Given that we observe an increase in levels of Task3 mRNA during activity, we wanted to investigate whether this coupled with an increase in Task3 protein expression that could regulate $\mathrm{K}^{+}$leak currents during periods of prolonged neuronal activity. To analyse this, we treated primary cortical neurons with $50 \mu \mathrm{M}$ glutamate for 2 mins followed by $1 \mathrm{~h}$ recovery, as in the previous experiments for mRNA quantification. Cortical cell lysates were analysed through Western blotting for Task3 expression with $50 \mu \mathrm{M}$ glutamate compared to a media change control (Figure 6D), where we observe an increase in Task3 protein translation of $~ 1.6-$ fold upon treatment with $50 \mu \mathrm{M}$ glutamate. These data indicate that Task3 mRNA and protein are both responsive to neuronal activity, with Task3 upregulation likely to play a role in maintaining membrane conductance to $\mathrm{K}^{+}$during the neuronal activity changes associated with synaptic plasticity. 


\section{DISCUSSION}

In silico and bioinformatic analyses predict the presence of over 10,000 potential G4 (pG4) sequences within the human transcriptome (16). Despite recent evidence suggesting that $\mathrm{G} 4 \mathrm{~s}$ are potentially globally un-folded in vivo (64), there is a wealth of evidence in support for $\mathrm{G} 4$ formation in vivo, ranging from the visualisation of their presence in both the nuclei and cytoplasm of cells through the generation of the G4 specific antibody, BG4 (65), to live cell imaging utilising fluorescent G4-specific ligands such as IMT (66). Similarly, the effect that these G4-specific ligands have on genomic stability as well as transcriptional and translational activity at pG4 regions also suggests maintenance of these structures in vivo (11).

In this study, we sought to investigate the functional influence of a 5' UTR potential G4-forming (GGN) ${ }_{13}$ repeat on the localisation and regulated expression of Task3 mRNA. Through biophysical, biochemical, electrophysiological and cell culture approaches, we have gathered substantial evidence to suggest that this $(G G N)_{13}$ repeat forms a stable parallel $G 4$ structure that inhibits translation of the potassium two-pore domain leak channel Task3 mRNA. Translational repression can be relieved endogenously and exogenously by the primary $\mathrm{G} 4$ helicase, DHX36. A shift of the membrane potential (reduction from -33.6 to $-68.4 \mathrm{mV}$ ) indicates that protein expression and plasma membrane expression also take place and result in modification of $\mathrm{K}^{+}$leak current. Further, our data suggest that the presence of this $5^{\prime}$ UTR G4 is necessary for correct neurite localisation of Task3 mRNA in primary neuronal cultures, providing a new insight into potential mechanisms controlling the regulated expression of $\mathrm{K} 2 \mathrm{P}$ channels.

G4s are stabilised by monovalent cations within the central electronegative pore, due to inward orientation of the electron-rich carbonyl groups from each guanine. $\mathrm{K}^{+}$shows the strongest co-ordinating ability due to its ionic radius, with $\mathrm{Na}^{+}$showing weak stabilisation and $\mathrm{Li}^{+}$unable to stabilise $\mathrm{G} 4 \mathrm{~s}(4,67)$. $\mathrm{K}^{+}$is the most abundant exchangeable cation in the body, with intracellular concentrations of $\mathrm{K}^{+}$at $\sim 150$ $\mathrm{mM}$ through the action of different $\mathrm{K}^{+}$transporters/channels (68). We therefore based our biophysical experiments around optimal intracellular $\mathrm{K}^{+}$concentrations of $150 \mathrm{mM}$. Through CD, Task3 (GGN) $)_{13}$ exhibited all of the expected classical G4 characteristics, including a strong dependency on $\mathrm{K}^{+}$ concentration, an inhibition of G4 formation through DMS methylation at the N7 position of guanine, and strong thermostability. These characteristics were lost in the absence of $\mathrm{K}^{+}$and also when the sequence was complemented to a $(\mathrm{CCN})_{13}$ repeat, inhibiting $\mathrm{G} 4$ formation whilst still allowing any potential GC duplex formation. Similarly, in the absence of $\mathrm{K}^{+}$and when complemented with $(\mathrm{CCN})_{13}$ the CD spectra were similar to that observed for a duplex-forming control. These data suggest that under physiological conditions, Task3 $(G G N)_{13}$ forms a stable parallel G4, however under nonphysiological $\mathrm{K}^{+}$conditions, it adopts an alternate structure, likely a duplex in the absence of stabilising $\mathrm{K}^{+}$ions. This was not observed for the NRAS WT G4, where G4 formation was maintained under all conditions except upon DMS-induced N7 methylation of guanine, suggesting that this is likely due to the repeating nature of $(\mathrm{GGN})_{13}$, not just because of $\mathrm{G} 4$ formation. In vivo this may suggest a more complex equilibrium between the two structures depending on cellular ionic conditions, a process that has previously been observed for other GC rich G4s (50).

When investigating the $\mathrm{G} 4$ influence on Task3 expression, several considerations were made to ensure physiological representation. Codon selection and amino acid composition is known to influence translation rate and efficiency post-initiation (69). Similarly, overexpression of $\mathrm{K}^{+}$leak channels perturbs cell signalling and intracellular $\mathrm{K}^{+}$conductance (70), which could therefore influence $\mathrm{G} 4$ folding and give a non-physiological representation of the action of the Task3 5' UTR G4. To overcome this, we designed Task 3 constructs that translate the same peptides possessing only the $\mathrm{N}$-terminal cytoplasmic and first transmembrane domains with a C-terminal FLAG tag. This avoided formation of functional Task3 $\mathrm{K}^{+}$ channels that would alter intracellular $\mathrm{K}^{+}$concentrations, whilst maintaining physiological codon selection post-translation initiation. We find that the G4 located in the 5' UTR of Task3 elicited $\sim 6$-fold decrease in translation of Task3 ${ }^{\mathrm{M} 1}-3 \mathrm{~F}$ peptides compared to when the (GGN) 13 repeat was deleted, a similar effect to that originally observed for the NRAS proto-oncogene 5' UTR G4 (14). G4s are 
prevalent within oncogenes, which has been suggested as a mechanism to buffer the overexpression of oncogenic proteins (71). The overexpression of Task3 and other $\mathrm{K}^{+}$leak channels alters cellular $\mathrm{K}^{+}$ conductance and has been implicated in a number of cancers $(72,73)$, suggesting this $5^{\prime}$ UTR G4 may control the regulated low level expression of Task3 required for normal physiological expression. In contrast, dysfunction and knockdown of Task3 leak channels leads to impaired neuronal migration of cerebral cortical neurons in the developing murine brain and the maternally imprinted intellectual disability Birk-Barel mental retardation $(35,74)$. Taken together, these data suggest that Task3 expression sits within a very narrow physiological window, which the 5' UTR G4 may be central to regulating.

DHX36 (also known as RHAU and G4R1) is a G4-specific helicase and has been shown to bind preferentially to $\mathrm{G} 4$ and G-rich sequences on over 4500 mRNA transcripts, preventing accumulation of translationally repressed mRNAs (53). Chen et al. recently co-crystallised DHX36 bound to the c-Myc $\mathrm{G} 4$, providing valuable insight into the mechanisms underpinning helicase mediated $\mathrm{G} 4$ unwinding (75). A mechanism of non-processive unwinding of G4es has been proposed, suggesting a preferential ATPindependent mechanism for DHX36 unwinding of RNA G4s, differing to that for DNA G4s $(76,77)$. Though Task3 had not previously been identified as a DHX36 target in large scale DHX36 interaction studies, we show here that Task3 mRNA is a functional target of DHX36, thereby relieving the translational repression elicited by the $5^{\prime}$ UTR G4 and increasing cellular $\mathrm{K}^{+}$leak currents specific to Task3. The disparity in changes in resting membrane potential when overexpressing DHX36 in the presence of endogenous vs exogenous levels of Task 3 mRNA suggest that Task 3 is one of the major targets of DHX36 that would be responsible for increasing $\mathrm{K}^{+}$leak currents. Task 3 can be expressed as a homodimer or co-expressed with its paralog Task1 as a functional heterodimer (78), with database sequences for Task1 mRNA suggesting the presence of a similar GGN repeat within its 5 ' UTR. Task1 sequencing shows a (GGC) 4 repeat present at the very 5' end of the 5' UTR, which may in fact be an incomplete sequence and might show more similarity in length and composition to Task3 if fully sequenced. Similarly, translation of the ATP-sensitive inward rectifier $\mathrm{K}^{+}$channel $\mathrm{KCNJ} 11$ was recently shown to be regulated by a G4 structure within its 3' UTR (79), which taken together suggest a complex combination of both cis- and trans-acting control mechanisms for expression of Task3 and other potassium channels in vivo.

It has been proposed that $\mathrm{G} 4 \mathrm{~s}$ are also a key driver of subcellular localisation of particular mRNAs. For instance, Subramanian et al., 2011 found that of the identified dendritic mRNAs, approximately $30 \%$ had sequences in their 3' UTRs predicted to form G4 structures (21). Mutating these potential G4 forming sequences showed that delivery of PSD-95 and CaMKIla mRNA to neurites of cultured primary cortical neurons was dependent on the presence of the G4-forming sequence within their 3' UTRs (21, 22, 54). Until now, the majority of localisation signals have been attributed to 3' UTR motifs, however, Muslimov et al. showed that insertion of the FXS associated FMR1 5' UTR (CGG) 24 repeat into a-tubulin 5' UTR induced re-localisation from the neuronal somata to dendrites of cultured rat sympathetic neurons (80). Here, we show that the endogenously present $(G G N)_{13}$ repeat, containing two separate GGC tracts of 5 and 4 repeating units, within the 5' UTR of Task3 mRNA is also able to facilitate neurite localisation. Upon mutation and deletion of the (GGN) ${ }_{13}$ G4 sequence, the distance that Task3 mRNA was detected from the cell body of cultured mouse cortical neurons was reduced by 59 and $83 \%$ respectively (Figure $5 \mathrm{C}$ ), suggesting a dependence on the presence of the (GGN) ${ }_{13} \mathrm{G} 4$ structure for Task3 mRNA localisation. Task3 mRNA was also detected as dense puncta along intact neurite projections, as seen through the eGFP and DIC images for both Figures 5 and 6, suggesting that Task3 mRNA is likely to be packaged within messenger ribonucleoprotein (mRNP) complexes, as is observed for distally transported mRNAs within neurons (81-83). Further, the detection of DHX36 in the axonal projections (Figure 6B, right) also suggests the presence of the correct and relevant machinery able to overcome G4-induced translational repression within the same distal compartments as Task3 mRNA.

Current models of G4 regulated local translation of neuronal mRNAs postulate that G4 mRNA is transported in a translationally repressed state by G4 binding proteins (G4-RBPs) such as FMRP. Upon 
neuronal activity and mGluR activation, G4-RBPs such as FMRP release their G4 containing mRNA thereby partially relieving the translational repression and allowing for spatiotemporally regulated translation of key mRNAs $(63,83)$. For Task3, we observe both an increase in mRNA concentration and protein translation upon $50 \mu \mathrm{M}$ glutamate treatment, which could suggest a similar mechanism of activity dependent regulation as is seen for other neuronal G4 containing mRNAs. Axonal transport is reported to occur at speeds of less than $2 \mu \mathrm{m} / \mathrm{s}$ (84). For long-distance neuronal projections, the presence of translationally-repressed pools of mRNA at sites of neuronal activity is key to coupling this rapid increase of protein synthesis, due to delays in anterograde transport from the cell body over long distances. We hypothesise that the increase in membrane expression of Task3 leak channels is a mechanism of maintaining membrane conductance to $\mathrm{K}^{+}$during the neuronal activity. Therefore, a combination of readily-responsive, distally localised mRNA, as well as the slower replenishment of Task3 mRNA to these distal sites would likely be key to facilitating the increase in Task3 protein expression observed in response to neuronal activity.

Taken together, our data suggest that a novel (GGN) ${ }_{13}$ repeat within the 5' UTR of Task3 mRNA forms a parallel G4 that is responsible for the regulation of localisation and translation of Task3 K2P leak channels. Classical G4 helicases are able to overcome the translational repression elicited by the 5' UTR G4, thereby increasing cellular $\mathrm{K}^{+}$leak currents and decreasing resting membrane potentials. Task3 is a protein with a narrow window of physiological expression, with over- and under-expression leading to cancer and neurodevelopmental disorders respectively. Given our findings, we suggest that this 5' UTR G4 is central to the regulated expression of Task3 leak channels in vivo.

\section{DATA AVAILABILITY}

5' RACE sequencing data have been deposited in GenBank [Accession Number: MN510330]

Stellaris $®$ RNA FISH probe designer was used for Task3 mouse Quasar ${ }^{\circ} 570 \mathrm{~nm}$ design https://www.biosearchtech.com/support/tools/design-software/stellaris-probe-designer

QGRS Mapper: a web-based server for predicting G4es in nucleotide sequences http://www.bioinformatics.ramapo.edu/QGRS/index.php

\section{ACKNOWLEDGEMENTS}

We thank Professor Keith Fox and Dr Grace Hallinan for critically reading the manuscript.

\section{FUNDING}

This work was supported by the Gerald Kerkut Charitable Trust Studentships to C.J.M. and J.P.R.S. BBSRC [BB/L010097/1 to MJC, BB/L007576/1 to KD]. S.D.H was funded by an Alzheimer's Research UK South Coast Network summer internship.

\section{CONFLICT OF INTEREST}

We declare that there are no conflicts of interest whilst undertaking this work. 


\section{REFERENCES}

1. Ganser,L.R., Kelly,M.L., Herschlag,D. and Al-hashimi,H.M. (2019) The roles of structural dynamics in the cellular functions of RNAs. Nature Reviews Molecular Cell Biology, 20, 474-489.

2. Harrell Jr,W.A., Neidle,S. and Balasubramanian,S. (2006) Quadruplex Nucleic Acids The Royal Society of Chemistry.

3. Kankia,B. (2019) Stability Factors of the Parallel Quadruplexes: DNA Versus RNA. The Journal of Physical Chemistry B, 123, 1060-1067.

4. Bhattacharyya,D., Arachchilage,G.M. and Basu,S. (2016) Metal Cations in G-Quadruplex Folding and Stability. Frontiers in Chemistry, 4, 1-14.

5. Lacroix,L., Mergny,J., Cian,A. De, Ghelab,A. and Sacca,B. (2005) Kinetics of tetramolecular quadruplexes. Nucleic Acids Research, 33, 81-94.

6. Guiset,H., Daniela,M., Richard,D., Silke,B. and Sigel,R.K.O. (2016) Distinct differences in metal ion specificity of RNA and DNA G-quadruplexes. Journal of Biological Inorganic Chemistry, 21, 975986.

7. Ravichandran,S., Kim,Y., Bansal,V., Ghosh,A., Kim,K. and Id,J.A. (2018) Genome-wide analysis of regulatory G-quadruplexes affecting gene expression in human cytomegalovirus. PLoS Pathogens, 14, 1-24.

8. Rawal,P., Bhadra,V., Kummarasetti,R., Ravindran,J., Kumar,N., Halder,K., Sharma,R., Mukerji,M. and Das,S.K. (2006) Genome-wide prediction of G4 DNA as regulatory motifs : Role in Escherichia coli global regulation. Genome Research, 16, 644-655.

9. Smith,J.S., Chen,Q., Yatsunyk,L.A., Nicoludis,J.M., Garcia,M.S., Kranaster,R., Balasubramanian,S., Monchaud,D., Abramowitz,L., Schultz,D.C., et al. (2011) Rudimentary Gquadruplex - based telomere capping in Saccharomyces cerevisiae. Nature Structural \& Molecular Biology, 18, 478-485.

10. Huppert,J.L., Fernando,H., Sewitz,S., Darot,J., Tavare,S. and Balasubramanian,S. (2009) Genome-wide analysis of a G-quadruplex-specific single-chain antibody that regulates gene expression. Nucleic Acids Research, 37, 6716-6722.

11. Siddiqui-jain,A., Grand,C.L., Bearss,D.J. and Hurley,L.H. (2002) Direct evidence for a Gquadruplex in a promoter region and its targeting with a small molecule to repress c-MYC transcription. Proceedings of the National Academy of Sciences of the United States of America, 99, 11593-11598.

12. Gray,L.T., Vallur,A.C., Eddy,J. and Maizels,N. (2014) G quadruplexes are genomewide targets of transcriptional helicases XPB and XPD. Nature Chemical Biology, 10, 313-318.

13. Huang,H., Zhang,J., Harvey,S.E., Hu,X. and Cheng,C. (2017) RNA G-quadruplex secondary structure promotes alternative splicing via the RNA-binding protein hnRNPF. Genes \& Development, 31, 2296-2309.

14. Kumari,S., Bugaut,A., Huppert,J.L. and Balasubramanian,S. (2007) An RNA G-quadruplex in the 5'UTR of the NRAS proto-oncogene modulates translation. Nature Chemical Biology, 3, 218221.

15. Bugaut,A. and Balasubramanian,S. (2012) 5'UTR RNA G-quadruplexes : translation regulation 
and targeting. Nucleic Acids Research, 40, 4727-4741.

16. Beaudoin,J. and Perreault,J. (2010) 5'UTR G-quadruplex structures acting as translational repressors. Nucleic Acids Research, 38, 7022-7036.

17. Morris,M.J., Negishi,Y., Pazsint,C. and Schonhoft,J.D. (2010) An RNA G-Quadruplex Is Essential for Cap-Independent Translation Initiation in Human VEGF IRES. American Chemical Society, 132, 17831-17839.

18. Chen,E., Sharma,M.R., Shi,X., Agrawal,R.K. and Joseph,S. (2014) Fragile X Mental Retardation Protein Regulates Translation by Binding Directly to the Ribosome. Molecular Cell, 54, 407-417.

19. Rouleau,S., Glouzon,J.S., Brumwell,A. and Bisaillon,M. (2017) 3' UTR G-quadruplexes regulate miRNA binding. RNA, 23, 1172-1179.

20. Beaudoin,J. and Perreault,J. (2013) Exploring mRNA 3' UTR G-quadruplexes : evidence of roles in both alternative polyadenylation and mRNA shortening. Nucleic Acids Research, 41, 58985911.

21. Subramanian,M., Rage,F., Tabet,R., Flatter,E., Mandel,J.-L. and Moine,H. (2011) G-quadruplex RNA structure as a signal for neurite mRNA targeting. EMBO reports, 12, 697-704.

22. Ishiguro,A., Kimura,N., Watanabe,Y. and Watanabe,S. (2016) TDP-43 binds and transports Gquadruplex-containing mRNAs into neurites for local translation. Genes to Cells, 21, 466-481.

23. Zappulo,A., Bruck,D. Van Den, Mattioli,C.C., Franke,V., Imami,K., Mcshane,E., Morenoestelles,M., Calviello,L., Filipchyk,A., Peguero-sanchez,E., et al. (2017) RNA localization is a key determinant of neurite-enriched proteome. Nature Communications, 8, 1-12.

24. Shigeoka,T., Jung,J., Holt,C.E. and Jung,H. (2018) Axon-TRAP-RiboTag: Affinity Purification of Translated mRNAs from Neuronal Axons in Mouse In Vivo BT - RNA Detection: Methods and Protocols. In Gaspar,I. (ed), Methods in Molecular Biology. Springer New York, New York, NY, pp. 85-94.

25. Shigeoka,T., Jung,H., Jung,J., Lin,J.Q., Amieux,P.S., Holt,C.E., Shigeoka,T., Jung,H., Jung,J., Turner-bridger,B., et al. (2016) Dynamic Axonal Translation in Developing and Article Dynamic Axonal Translation in Developing and Mature Visual Circuits. Cell, 166, 181-192.

26. Cajigas,J., Tushev,G., Will,T.J., Dieck,S., Fuerst,N. and Schuman,E.M. (2012) The Local Transcriptome in the Synaptic Neuropil Revealed by Deep Sequencing and High-Resolution Imaging. Neuron, 74, 453-466.

27. Tushev,G., Glock,C., Biever,A., Jovanovic,M., Schuman,E.M., Biever,A., Jovanovic,M. and Schuman,E.M. (2018) Alternative 3' UTRs Modify the Localization, Regulatory Potential, Stability, and Plasticity ofmRNAs in Neuronal Compartments. Neuron, 98, 495-511.

28. Holt,C.E., Martin,K.C. and Schuman,E.M. (2019) Local translation in neurons: visualization and function. Nature Structural \& Molecular Biology, 26, 557-566.

29. Todd,P.K., Oh,S.Y., Krans,A., He,F., Sellier,C., Frazer,M., Renoux,A.J., Chen,K., Scaglione,K.M., Basrur,V., et al. (2013) CGG Repeat-Associated Translation Mediates Neurodegeneration in Fragile X Tremor Ataxia Syndrome. Neuron, 78, 440-455.

30. Gitler,A.D. and Tsuiji,H. (2016) There has been an awakening: Emerging mechanisms of C9orf72 mutations in FTD/ALS. Brain Research, 1647, 19-29. 
31. Reddy,K., Zamiri,B., Stanley,S.Y.R., Macgregor,R.B. and Pearson,C.E. (2013) The Diseaseassociated r(GGGGCC)n Repeat from the C9orf72 Gene Forms Tract Length-dependent Uniand Multimolecular RNA G-quadruplex structures. Journal of Biological Chemistry, 288, 98609866.

32. Simone,R., Fratta,P., Neidle,S., Parkinson,G.N. and Isaacs,A.M. (2015) G-quadruplexes : Emerging roles in neurodegenerative diseases and the non-coding transcriptome. FEBS Letters, 589, 1653-1668.

33. Enyedi,P. and Czirjak,G. (2010) Molecular Background of Leak K+ Currents : Two-Pore Domain Potassium Channels. Physiological Reviews, 90, 559-605.

34. Brickley,S.G., Aller,M.I., Sandu,C., Veale,E.L., Alder,F.G., Sambi,H., Mathie,A. and Wisden,W. (2007) TASK-3 Two-Pore Domain Potassium Channels Enable Sustained High-Frequency Firing in Cerebellar Granule Neurons. The Journal of Neuroscience, 27, 9329-9340.

35. Barel,O., Shalev,S.A., Ofir,R., Cohen,A., Zlotogora,J., Shorer,Z., Mazor,G., Finer,G., Khateeb,S., Zilberberg,N., et al. (2008) Maternally Inherited Birk Barel Mental Retardation Dysmorphism Syndrome Caused by a Mutation in the Genomically Imprinted Potassium Channel KCNK9. The American Journal of Human Genetics, 83, 193-199.

36. Coldwell,M.J., Sack,U., Cowan,J.L., Barrett,R.M., Vlasak,M., Sivakumaran,K. and Morley,S.J. (2012) Multiple isoforms of the translation initiation factor elF4GII are generated via use of alternative promoters, splice sites and a non-canonical initiation codon. Biochemical Journal, 448, 1-11.

37. Ho,T.T.G., Merajver,S.D., Lapie,C.M., Nusgens,B. V and Deroanne,C.F. (2008) RhoA-GDP Regulates RhoB Protein Stability. Journal of Biological Chemistry, 283, 21588-21598.

38. Deinhardt,K., Kim,T., Spellman,D.S., Mains,R.E., Eipper,B.A., Neubert,T.A., Chao,M. V and Hempstead,B.L. (2011) Neuronal Growth Cone Retraction Relies on Proneurotrophin Receptor Signaling Through Rac. Science Signalling, 4, 1-9.

39. Katayama,T., Imaizumi,K., Sato,N., Miyoshi,K., Kudo,T., Hitomi,J., Morihara,T., Yoneda,T., Gomi,F., Mori,Y., et al. (1999) Presenilin-1 mutations downregulate the signalling pathway of the unfolded-protein response. Nature Cell Biology, 1, 479-485.

40. Willis,D.E. and Twiss,J.L. (2011) Profiling Axonal mRNA Transport. In Gerst,J.E. (ed), RNA Detection and Visualization: Methods and Protocols. Humana Press, Totowa, NJ, pp. 335-352.

41. Neher,E. and Sakmann,B. (1992) The Patch Clamp Technique. Scientific American, 266, 44-51.

42. Kirby,E.D., Kuwahara,A.A., Messer,R.L. and Wyss-Coray,T. (2015) Adult hippocampal neural stem and progenitor cells regulate the neurogenic niche by secreting VEGF. Proceedings of the National Academy of Sciences, 112, 4128 LP - 4133.

43. Malgowska,M., Gudanis,D., Kierzek,R. and Wyszko,E. (2014) Distinctive structural motifs of RNA G-quadruplexes composed of AGG, CGG and UGG trinucleotide repeats. Nucleic Acids Research, 42, 10196-10207.

44. Kikin,O., Antonio,L.D. and Bagga,P.S. (2006) QGRS Mapper : a web-based server for predicting G-quadruplexes in nucleotide sequences. Nucleic Acids Research, 34, 676-682.

45. Beaudoin,J., Jodoin,R. and Perreault,J. (2014) New scoring system to identify RNA G-quadruplex 
folding. Nucleic Acids Research, 42, 1209-1223.

46. Vorlícková,M., Kejnovská,I., Sagi,J., Renciuk,D. and Bednárova,K. (2012) Circular dichroism and Guanine quadruplexes. Methods, 57, 64-75.

47. Villar-guerra,R., Trent,J.O. and Chaires,J.B. (2018) G-Quadruplex Secondary Structure Obtained from Circular Dichroism Spectroscopy. Angewandte Chemi, 57, 1-6.

48. Kypr,J., Kejnovská,I., Renciuk,D. and Vorlickova,M. (2009) Circular dichroism and conformational polymorphism of DNA. Nucleic Acids Research, 37, 1713-1725.

49. Peattie,D.A. and Gilbert,W. (1980) Chemical probes for higher-order structure in RNA.

Proceedings of the National Academy of Sciences of the United States of America, 77, 46794682.

50. Bugaut,A., Murat,P. and Balasubramanian,S. (2012) An RNA Hairpin to G - Quadruplex Conformational Transition. Journal of the American Chemical Society, 134, 19953-19956.

51. Kaplan,O.I., Berber,B., Hekim,N. and Doluca,O. (2016) G-quadruplex prediction in E . coli genome reveals a conserved putative G-quadruplex-Hairpin-Duplex switch. Nucleic Acids Research, 44, 9083-9095.

52. Booy,E.P., Meier,M., Okun,N., Novakowski,S.K., Xiong,S. and Stetefeld,J. (2012) The RNA helicase RHAU ( DHX36 ) unwinds a G4-quadruplex in human telomerase RNA and promotes the formation of the P1 helix template boundary. Nucleic Acids Research, 40, 4110-4124.

53. Sauer,M., Juranek,S.A., Marks,J., Magis,A. De, Kazemier,H.G., Hilbig,D., Benhalevy,D., Wang,X., Hafner,M. and Paeschke,K. (2019) DHX36 prevents the accumulation of translationally inactive mRNAs with G4-structures in untranslated regions. Nature Communications, 10, 1-15.

54. Bicker,S., Khudayberdiev,S., Weiß,K., Zocher,K., Baumeister,S. and Schratt,G. (2013) The DEAH-box helicase DHX36 mediates dendritic localization of the neuronal precursor-microRNA134. Genes \& Development, 27, 991-996.

55. Thomas,P. and Smart,T.G. (2005) HEK293 cell line: A vehicle for the expression of recombinant proteins. Journal of Pharmacological and Toxicological Methods, 51, 187-200.

56. Zhang,Y., Gaetano,C.M., Williams,K.R., Bassell,G.J., Zhang,Y., Gaetano,C.M., Williams,K.R., Gary,J., Zhang,Y., Gaetano,C.M., et al. (2015) FMRP interacts with G-quadruplex structures in the 3 ' UTR of its dendritic target Shank1 mRNA. RNA Biology, 11, 1364-1374.

57. Cajigas,J., Will,T. and Schuman,E.M. (2010) Protein homeostasis and synaptic plasticity. EMBO, 29, 2746-2752.

58. Hou,L., Antion,M.D., Hu,D., Spencer,C.M., Paylor,R. and Klann,E. (2006) Dynamic Translational and Proteasomal Regulation of Fragile X Mental Retardation Protein Controls mGluRDependent Long-Term Depression. Neuron, 51, 441-454.

59. Rosenberg,T., Gal-ben-ari,S., Dieterich,D.C., Kreutz,M.R. and Ziv,N.E. (2014) The roles of protein expression in synaptic plasticity and memory consolidation. Frontiers in Neuroscience, 7, 1-14.

60. Soriano,J., Tlusty,T. and Moses,E. (2008) Development of input connections in neural cultures. Proceedings of the National Academy of Sciences of the United States of America, 105, 1375813763.

61. Langer,J.D., Schuman,E.M. and Schanzenba,C.T. (2018) Time- and polarity-dependent proteomic 
changes associated with homeostatic scaling at central synapses. eLife, 7, 1-20.

62. Bagal,A.A., Kao,J.P.Y., Tang,C. and Thompson,S.M. (2005) Long-term potentiation of exogenous glutamate responses at single dendritic spines. Proceedings of the National Academy of Sciences of the United States of America, 102, 3-8.

63. Narayanan,U., Nalavadi,V., Nakamoto,M., Pallas,D.C., Ceman,S., Bassell,G.J. and Warren,S.T. (2007) FMRP Phosphorylation Reveals an Immediate-Early Signaling Pathway Triggered by Group I mGluR and Mediated by PP2A. The Journal of Neuroscience, 27, 14349-14357.

64. Guo,J.U. and Bartel,D.P. (2016) RNA G-quadruplexes are globally unfolded in eukaryotic cells and depleted in bacteria. Science, 353, 5371 1-5.

65. Biffi,G., Antonio,M. Di, Tannahill,D. and Balasubramanian,S. (2013) Visualization and selective chemical targeting of RNA G-quadruplex structures in the cytoplasm of human cells. Nature Chemistry, 6, 75-80.

66. Zhang,S., Sun,H., Wang,L., Liu,Y., Chen,H., Li,Q., Guan,A., Liu,M. and Tang,Y. (2018) Real-time monitoring of DNA G-quadruplexes in living cells with a small-molecule fluorescent probe.

Nucleic Acids Research, 46, 7522-7532.

67. Guiset Miserachs,H., Donghi,D., Börner,R., Johannsen,S. and Sigel,R.K.O. (2016) Distinct differences in metal ion specificity of RNA and DNA G-quadruplexes. JBIC Journal of Biological Inorganic Chemistry, 21, 975-986.

68. Thier,S.O. (1986) Potassium physiology. The American Journal of Medicine, 80, 3-7.

69. Yu,C., Dang,Y., Zhao,F., Matthew,S., Yu,C., Dang,Y., Zhou,Z., Wu,C., Zhao,F., Sachs,M.S., et al. (2015) Codon Usage Influences the Local Rate of Translation Elongation to Regulate Cotranslational Protein Folding. Molecular Cell, 59, 744-754.

70. Huang,X. and Jan,L.Y. (2014) Targeting potassium channels in cancer. Journal of Cell Biology, 206, 151-162.

71. Eddy,J. and Maizels,N. (2006) Gene function correlates with potential for G4 DNA formation in the human genome. Nucleic Acids Research, 34, 3887-3896.

72. Bittner,S., Budde,T., Wiendl,H. and Meuth,S.G. (2010) From the Background to the Spotlight: TASK Channels in Pathological Conditions. Brain Pathology, 20, 999-1009.

73. Pei,L., Wiser,O., Slavin,A., Mu,D., Powers,S., Lily,Y.J. and Hoey,T. (2003) Oncogenic potential of TASK3 (Kcnk9) depends on K+ channel function. Proceedings of the National Academy of Sciences of the United States of America, 100, 7803-7807.

74. Bando,Y., Hirano,T. and Tagawa,Y. (2012) Dysfunction of KCNK Potassium Channels Impairs Neuronal Migration in the Developing Mouse Cerebral Cortex. Cerebral Cortex, 24, 1017-1029.

75. Chen,M.C., Tippana,R., Demeshkina,N.A., Murat,P., Balasubramanian,S., Myong,S. and FerréD'Amaré,A.R. (2018) Structural basis of G-quadruplex unfolding by the DEAH/RHA helicase DHX36. Nature, 558, 465-469.

76. Chen,M.C., Murat,P., Abecassis,K., Amar,A.R.F. and Balasubramanian,S. (2015) Insights into the mechanism of a G-quadruplex-unwinding DEAH-box helicase. Nucleic Acids Research, 43, 2223-2231.

77. Tippana,R., Chen,M.C., Demeshkina,N.A., Amaré,A.R.F. and Myong,S. (2019) RNA G- 
quadruplex is resolved by repetitive and ATP-dependent mechanism of DHX36. Nature

Communications, 10, 1-10.

78. Czirjak,G. and Enyedi,P. (2002) Formation of Functional Heterodimers between the TASK-1 and TASK-3 Two-pore Domain Potassium Channel Subunits. The Journal of Biological Chemistry, 277, 5426-5432.

79. Zhang,J., Wang,J., Li,F., Zhu,M., Wang,S., Cui,Q., Yuan,G., Zhou,J. and Xu,M. (2019) Normal expression of KCNJ11 is maintained by the G-quadruplex. International Journal of Biological Macromolecules, 138, 504-510.

80. Muslimov,I.A., Patel,M. V, Rose,A. and Tiedge,H. (2011) Spatial code recognition in neuronal RNA targeting: Role of RNA-hnRNP A2 interactions. Journal of Cell Biology, 194, 441-457.

81. Buchan,J.R. (2014) mRNP granules Assembly , function , and connections with disease. RNA, 11, 1019-1030.

82. Batish,M., Bogaard,P. Van Den, Russell,F. and Tyagi,S. (2012) Neuronal mRNAs travel singly into dendrites. Proceedings of the National Academy of Sciences of the United States of America, 109, 4645-4650.

83. Ferrari,F., Mercaldo,V., Piccoli,G., Sala,C., Cannata,S., Achsel,T. and Bagni,C. (2007) The fragile $X$ mental retardation protein - RNP granules show an mGluR-dependent localization in the postsynaptic spines. Molecular and Cellular Neuroscience, 34, 343-354.

84. Gibbs,K.L., Kalmar,B., Sleigh,J.N., Greensmith,L. and Schiavo,G. (2016) In vivo imaging of axonal transport in murine motor and sensory neurons. Journal of Neuroscience Methods, 257, 26-33. 
bioRxiv preprint doi: https://doi.org/10.1101/797423; this version posted October 10, 2019. The copyright holder for this preprint (which was not certified by peer review) is the author/funder, who has granted bioRxiv a license to display the preprint in perpetuity. It is made

A

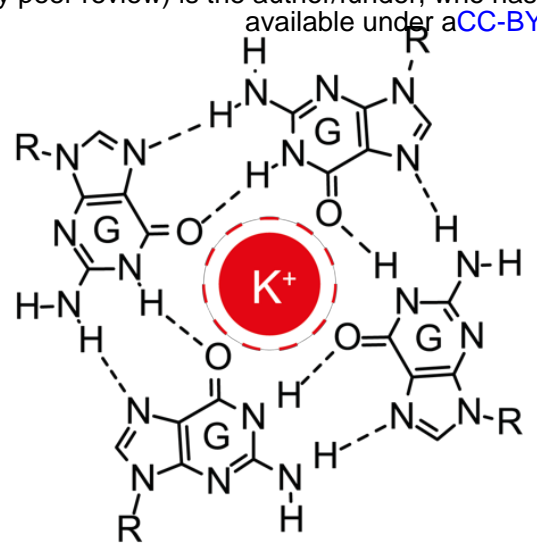

\section{B} $-131 \quad-120$

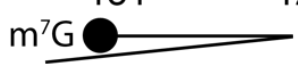
$-89$

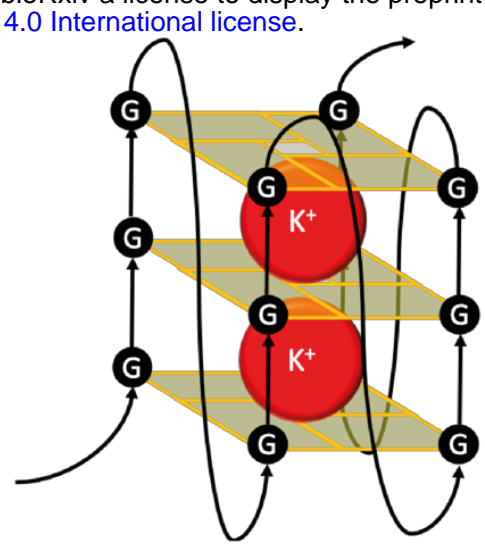

\section{GGAGGCGGCGGCGGCGGCGGAGGAGGAGGCGGCGGCGGC}

$\mathrm{AUG}+1$

$\mathrm{C}$

\begin{tabular}{|l|l|c|c|}
\hline \multicolumn{1}{|c|}{ Construct } & \multicolumn{1}{|c|}{ Sequence } & G4 Score 1 & G4 Score 2 \\
\hline Task3 WT (GGN) & \multicolumn{1}{|c|}{ WGAGGCGGCGGCGGCGGCGGAGGAGGAGGCGGCGGCGGC } & $21-59$ & 5.8 \\
\hline \multirow{2}{*}{ Task3 Ext (60 nt) } & $\begin{array}{l}\text { GCTTACAACTTGGAGGCGGCGGCGGCGGCGGAGGAGGAG } \\
\text { GCGGCGGCGGCCGCCGGGCGC }\end{array}$ & $21-59$ & 3.1 \\
\hline Task3 Comp & CCTCCGCCGCCGCCGCCGCCTCCTCCTCCGCCGCCGCCG & 0 & 0.167 \\
\hline NRAS WT G4 & GGGAGGGGCGGGTCTGGG & 40 & 20 \\
\hline NRAS Comp & CCCTCCCCGCCCAGACCC & 0 & 0.043 \\
\hline Duplex & AAAGCGCGCGCGCGAAAAACGCGCGCGCGCAAA & 0 & 1 \\
\hline
\end{tabular}

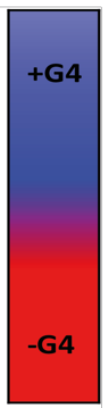

D

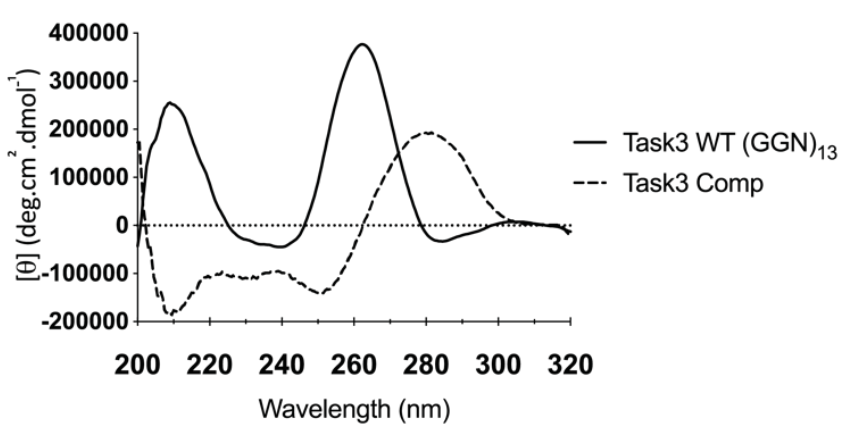

$\mathrm{F}$

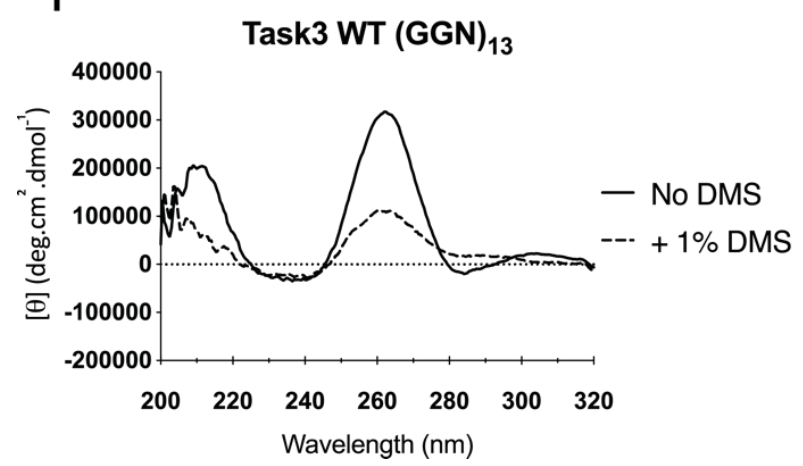

$E$

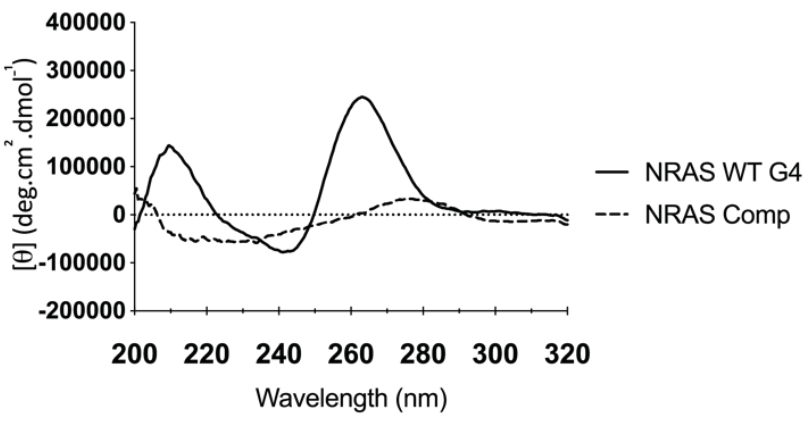

G

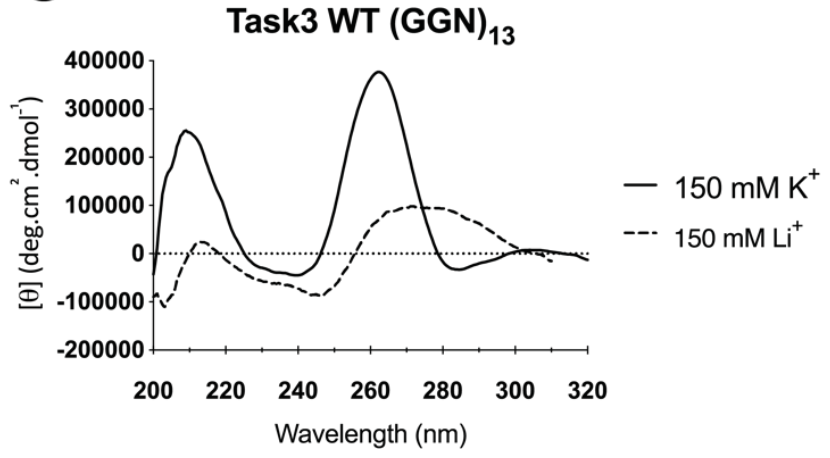

Figure 1 - Task3 mRNA contains a 5' UTR cap-proximal (GGN) 13 repeat that forms a parallel G4 (A) Schematic illustrating conformation of Hoogsteen bonded guanine-quartets (left), that stack into G4 structures stabilised by $\mathrm{K}^{+}$ions (right). (B) Map of Task3 mRNA indicating the (GGN) 13 repeat within the 5' UTR, as identified by 5' RACE (GenBank: MN510330). (C) In silico prediction of Task3 experimental oligos structural formation based upon nucleotide composition and location - G4 score 1 and 2 refer to the $\mathrm{G} 4$ prediction tools outlined in methods. The CD spectra of $10 \mu \mathrm{M}$ Task3 WT (GGN) 13 and Task3 Complementary oligos (D) or NRAS WT G4 or NRAS Complementary oligos (E) folded in potassium phosphate buffer supplemented with $\mathrm{KCl}$ to $150 \mathrm{mM} \mathrm{K}^{+}$. (F) The CD spectra of $10 \mu \mathrm{M}$ Task3 WT (GGN) 13 oligos folded with or without pre-treatment of $1 \%$ dimethyl sulphate (DMS) to induce N7 methylation of guanine. (G) The CD spectra of $10 \mu \mathrm{M}$ Task3 WT (GGN) 13 oligos folded in potassium phosphate buffer supplemented with $\mathrm{KCl}$ to $150 \mathrm{mM} \mathrm{K}^{+}$to facilitate $\mathrm{G} 4$ formation (CD spectra overlaid from 1D) or folded in sodium phosphate buffer supplemented with $\mathrm{LiCl}$ to $150 \mathrm{mM} \mathrm{Li}$ to inhibit $\mathrm{G} 4$ formation. CD spectra were obtained from five repeated acquisitions to increase the signal:noise ratio with a representative trace shown. 
bioRxiv preprint doi: https://doi.org/10.1101/797423; this version posted October 10, 2019. The copyright holder for this preprint (which was not certified by peer review) is the author/funder, who has granted bioRxiv a license to display the preprint in perpetuity. It is made available under aCC-BY-NC-ND 4.0 International license.
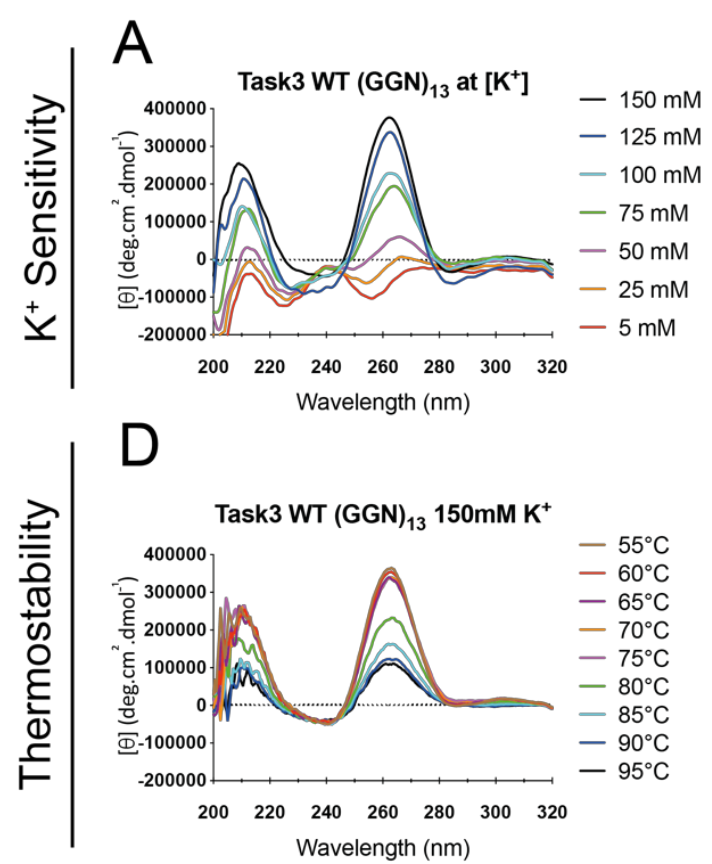

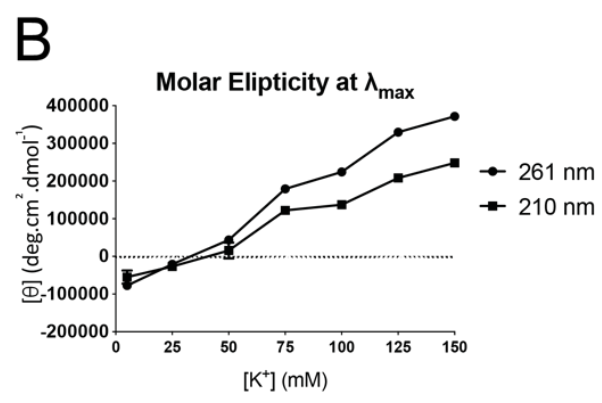

\section{$E$}

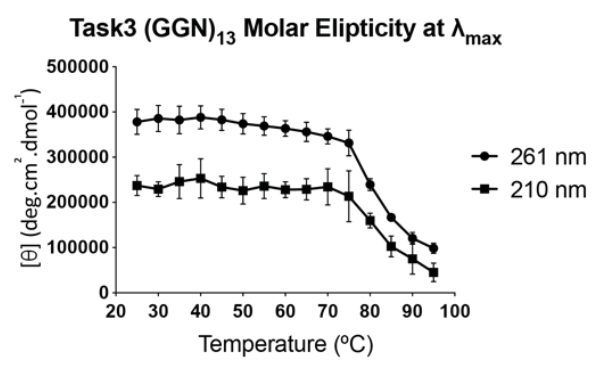

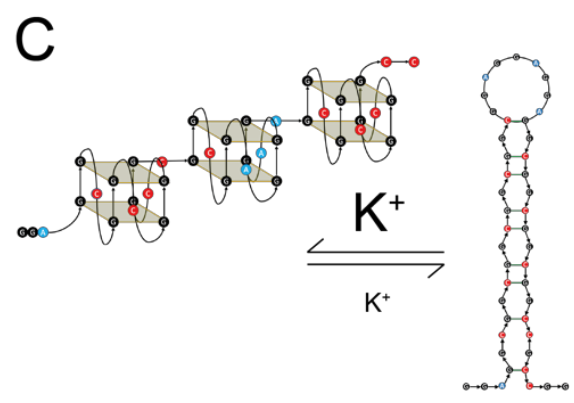

$\mathrm{F}$

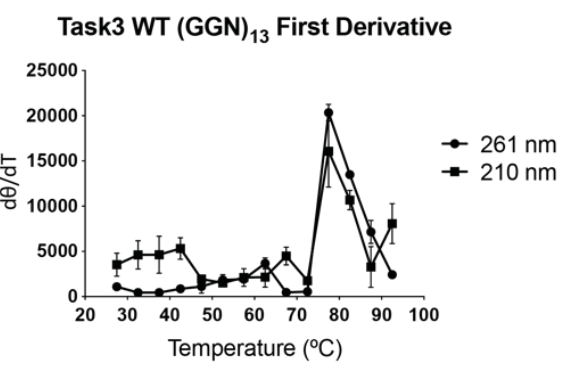

Figure 2 - Task3 WT (GGN) ${ }_{13}$ G4 formation is highly thermostable and sensitive to $\mathrm{K}^{+}$- (A) The CD spectra of $10 \mu \mathrm{M}$ Task3 WT (GGN) $)_{13}$ oligos folded in potassium phosphate buffer and supplemented with $\mathrm{KCl}$ to a free $\left[\mathrm{K}^{+}\right]$of between 5-150 mM. (B) Molar ellipticity at the $\lambda_{\max }$ of 210 and $261 \mathrm{~nm}$ for Task3 WT (GGN) ${ }_{13}$ at increasing [K+]. (C) Schematic illustrating the proposed balance of structural conformations of Task3 (GGN) $)_{13}$ at low vs high $\mathrm{K}^{+}$ concentrations. The CD thermal profile of $10 \mu \mathrm{M}$ Task3 WT (GGN) $)_{13}(\mathrm{D})$ which was quantified at the two $\lambda_{\max }$ of 210 and $261 \mathrm{~nm}(\mathbf{E})$ with estimation of melting temperature through first derivative calculations $(\mathbf{F})$. $N=3$ replicates of 5 repeated acquisitions for signal:noise correction with representative traces shown for each condition. 

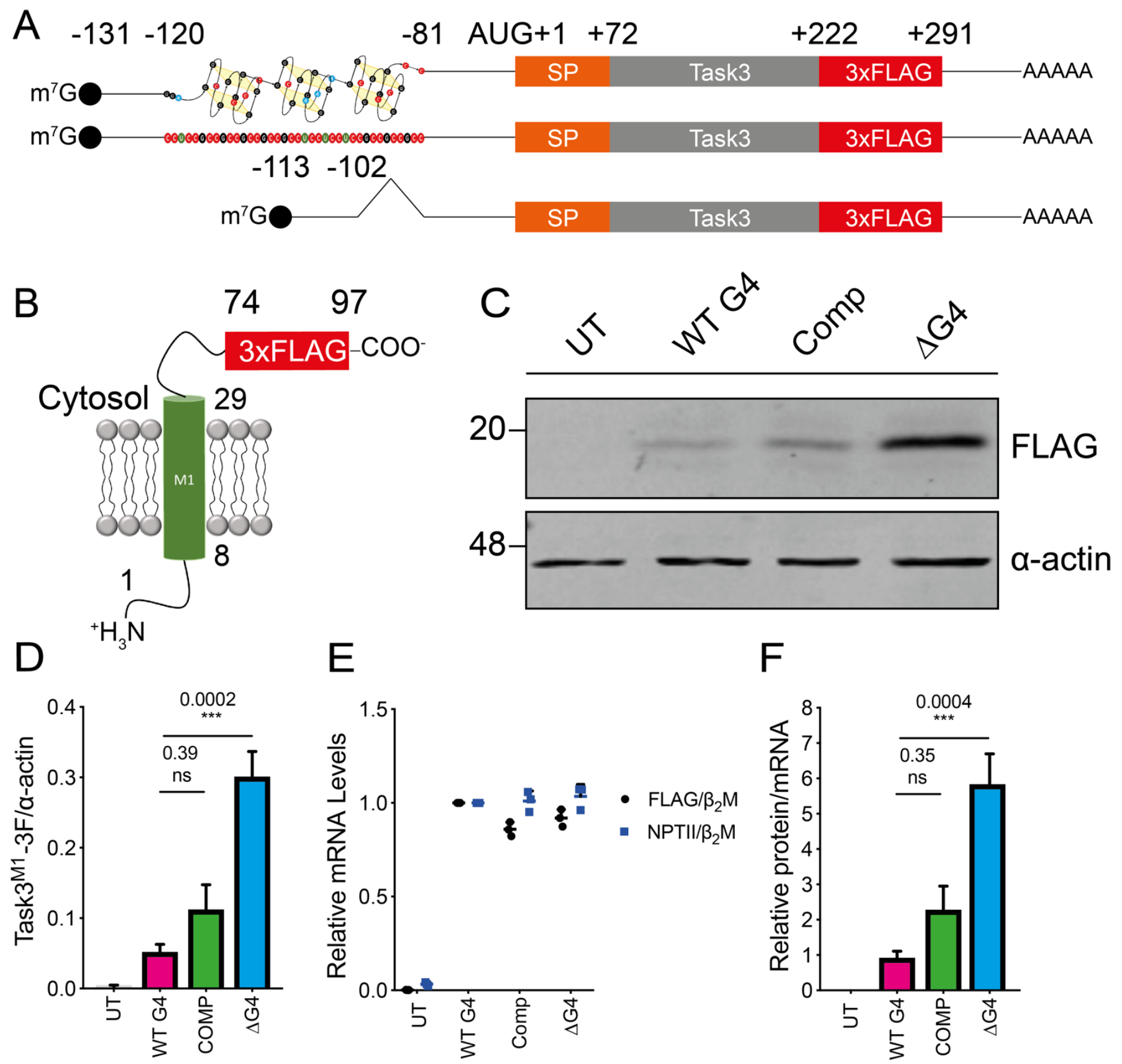

Figure 3 - Task3 5' UTR G4 inhibits translation of Task3-FLAG peptides - (A) Schematic of the mRNA transcripts produced by the different Task3 mutant 5' UTR constructs, possessing either the wild-type full length 5' UTR, complementary $(C C N)_{13}$ repeat mutant, or a $(G G N)_{13}$ deletion $(\Delta G 4)$ mutant. SP - signal peptide. (B) All constructs translate the identical 97 amino acid peptides (Task3 ${ }^{\mathrm{M} 1}-3 \mathrm{~F}$ ) allowing for comparison of different translation efficiencies that arise from different structural species present within Task3 5' UTR. (C) Western blotting of HEK-293 lysates transfected with each Task3 mutant 5' UTR construct. (D) Quantification of Task3 ${ }^{\mathrm{M} 1}$-FLAG expression normalised to a-actin expression. (E) Mutant 5' UTR Task3 ${ }^{M 1}$-FLAG mRNA transcript abundance normalised to endogenous HEK-293 $\beta_{2} \mathrm{M}$ (Black) or the internal vector control NPTII normalised to HEK-293 $\beta_{2} \mathrm{M}$ (Blue) for transfection control. (F) Relative translation efficiency attributed to each of the wild-type or mutant Task3 5' UTR mRNA transcripts where Task3 WT G4 5' UTR $=1 . \mathrm{N}=3$ biological replicates where error bars represent SEM. Statistical analyses were carried out by one-way ANOVA $\mathbf{D}-(F(3,8)=25.84, p=0.0002), \mathbf{F}-(F(3,8)=21.42, p=$ 0.0004 ) with post-hoc Sidak's multiple comparison tests, p-values shown. UT = untransfected. 

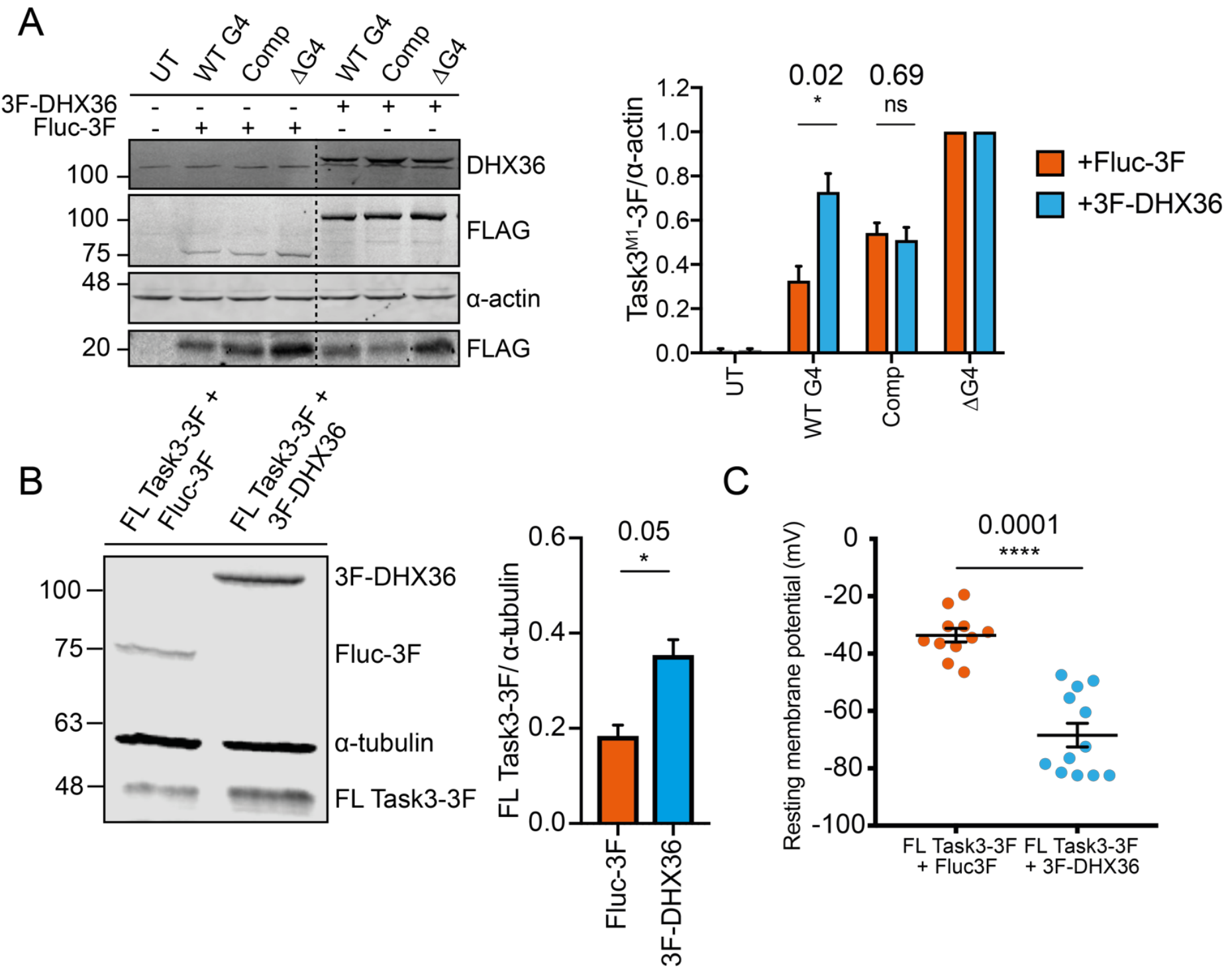

Figure 4 - The translation inhibition induced by the Task3 5' UTR G4 is relieved through overexpression of the G4 specific helicase DHX36 - (A) Western blotting of HEK-293 lysates co-transfected with each Task3 mutant 5' UTR construct and either a non-G4 interacting co-transfection control (Fluc-3F) or the G4 resolving helicase DHX36 (Left). Quantification of Task3 ${ }^{\mathrm{M} 1}$-3F expression normalised to $\alpha$-actin expression. In each co-transfection condition, Task3 ${ }^{\mathrm{M} 1}-3 \mathrm{~F}$ expression values for the Task3 5' UTR mutant constructs were normalised to the $\Delta \mathrm{G} 4$ control (Right). (B) Western blotting of HEK293 lysates transfected with Fluc-3F or 3F-DHX36. Membranes were blotted using anti-FLAG antibody to identify expression of Fluc-3F, 3F-DHX36 as well as FL Task3-3F and anti-a-tubulin for a-tubulin (Left), with exogenous FL Task3-3F expression quantification normalised to a-tubulin (Right). (C) Whole cell patch clamp recordings of HEK293 cells co-transfected with FL Task3-3F and either Fluc-3F or 3F-DHX36 (Left). Western blotting of HEK293 cell lysates under the same transfection conditions and time-points (Right). $\mathrm{N}=3$ biological replicates where error bars represent SEM. Statistical analyses were carried out by unpaired one-tailed T-tests, p-values shown. UT = untransfected. 
bioRxiv preprint doi: https://doi.org/10.1101/797423; this version posted October 10, 2019. The copyright holder for this preprint (which was not certified by peer review) is the author/funder, who has granted bioRxiv a license to display the preprint in perpetuity. It is made

A
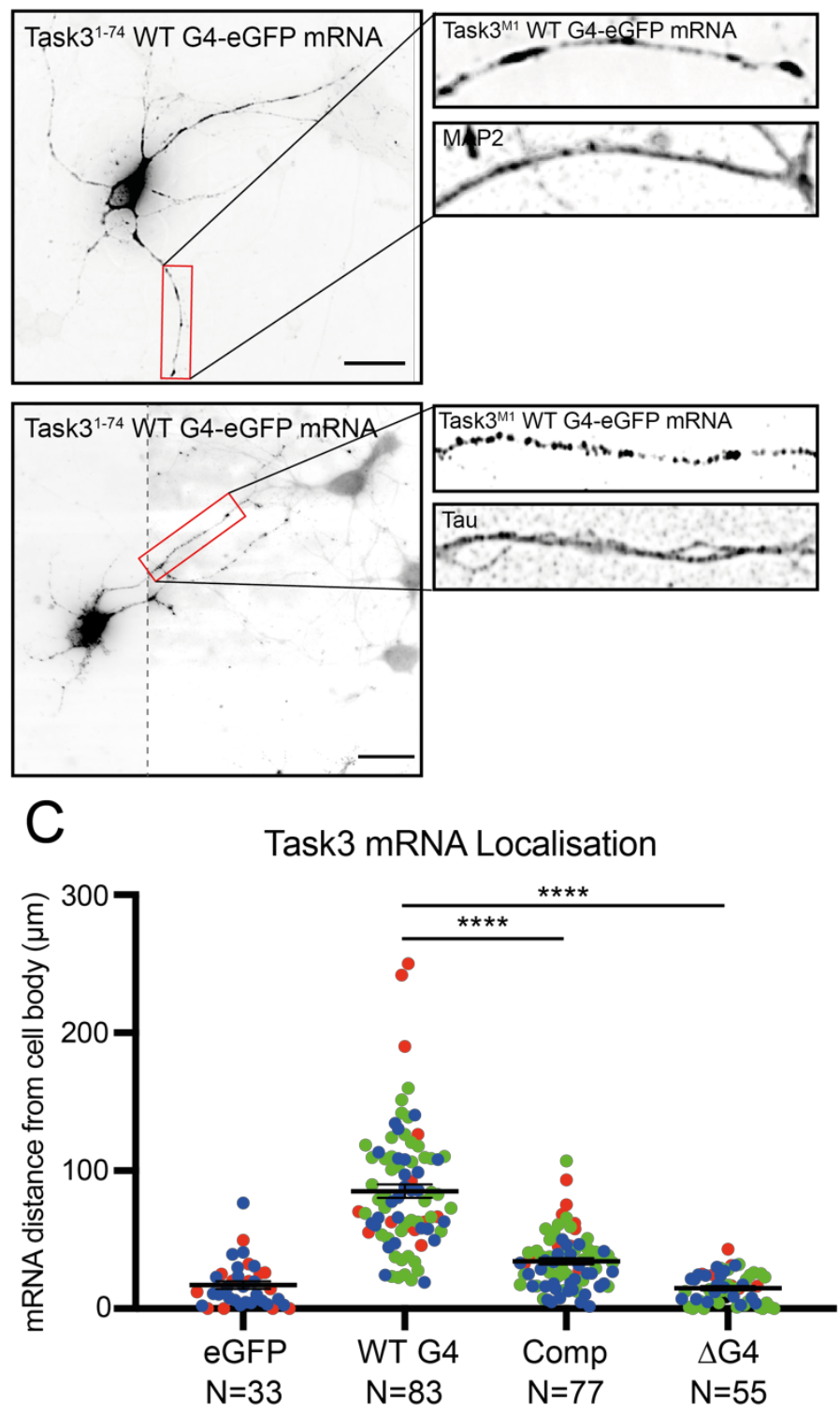

B
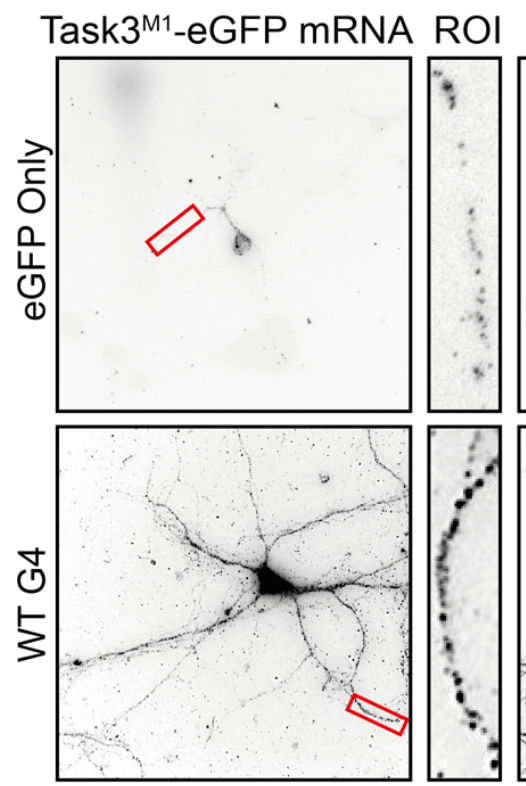

Fluc-3F
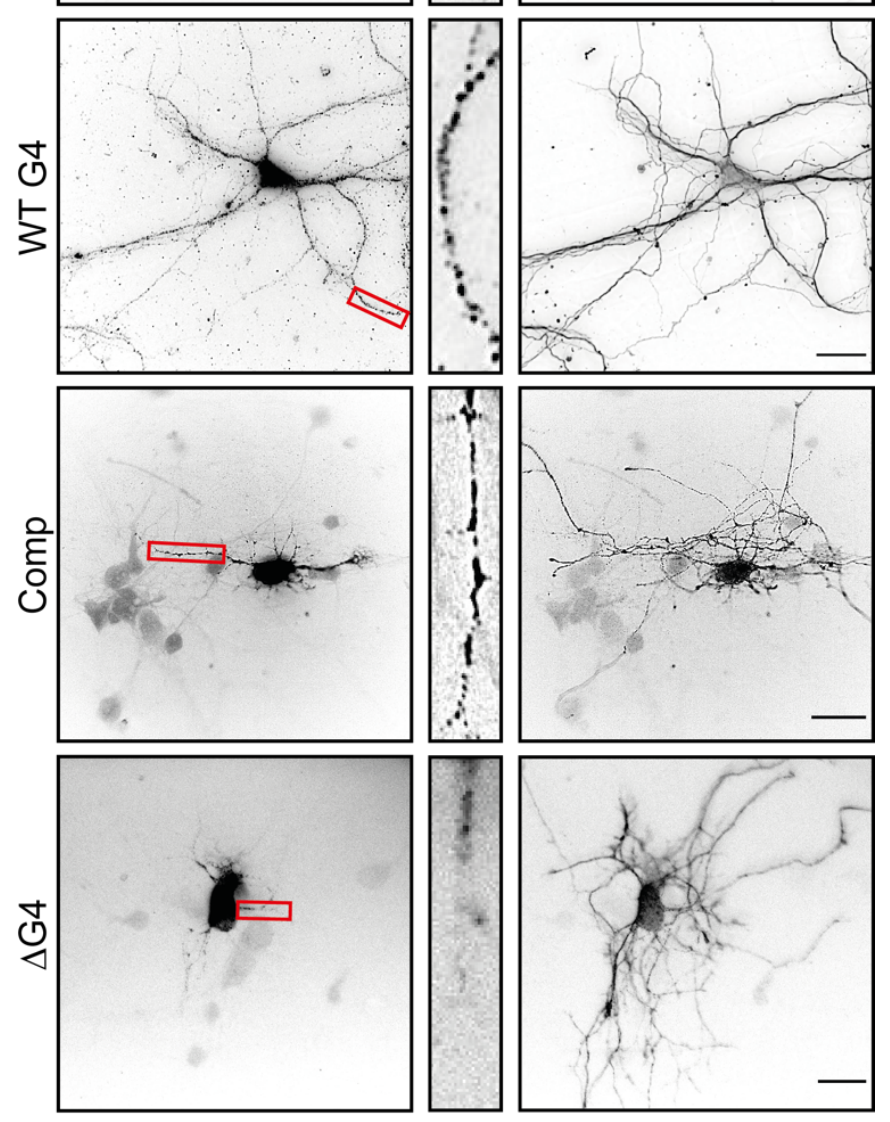

Figure 5 - Task3 5' UTR (GGN) 13 repeat is required for distal neurite localisation of Task3 mRNA - (A) RNA FISH of DIV10 embryonic murine cortical neurons transfected with WT G4 Task3 ${ }^{\mathrm{M} 1}$-eGFP. Cells were hybridised with anti-eGFP probes and anti-MAP2/Tau primary antibodies to determine neurite localisation of exogenous Task3 mRNA. Image 2 was taken at two exposures to define mRNA granules in both the cell body and neurites with the respective images merged (dotted line). Original un-edited images available in Figure S4. (B) RNA FISH of transfected DIV10 embryonic murine cortical neurons co-transfected with mutant G4 5' UTR Task3 ${ }^{\mathrm{M} 1}$-eGFP and Fluc-3F as a soluble whole-cell tracker. Cells were hybridised with anti-eGFP probes and anti-FLAG M2 primary antibody showing localisation of exogenous mutant G4 $5^{\prime}$ UTR Task3 ${ }^{\mathrm{M} 1}$-eGFP $\mathrm{mRNA}$ in comparison to whole-cell staining. (C) The distance of exogenous mutant G4 5' UTR Task3 ${ }^{\mathrm{M} 1}$-eGFP mRNA from the cell body, quantified in Fiji for cells possessing neurites $\geq 100 \mu \mathrm{m}$ in length. Number of neurites analysed is shown from 3 blinded biological replicates (coloured groups), where error bars represent SEM. Statistical analyses were carried out by one-way ANOVA $(F(3,247)=89.01, p<0.0001)$, with post-hoc Sidak's multiple comparison tests; ${ }^{* \star *} p<0.0001$. Scale bar $=$ $20 \mu \mathrm{m}$. 
A

1

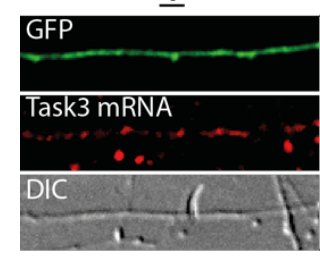

$\underline{2}$
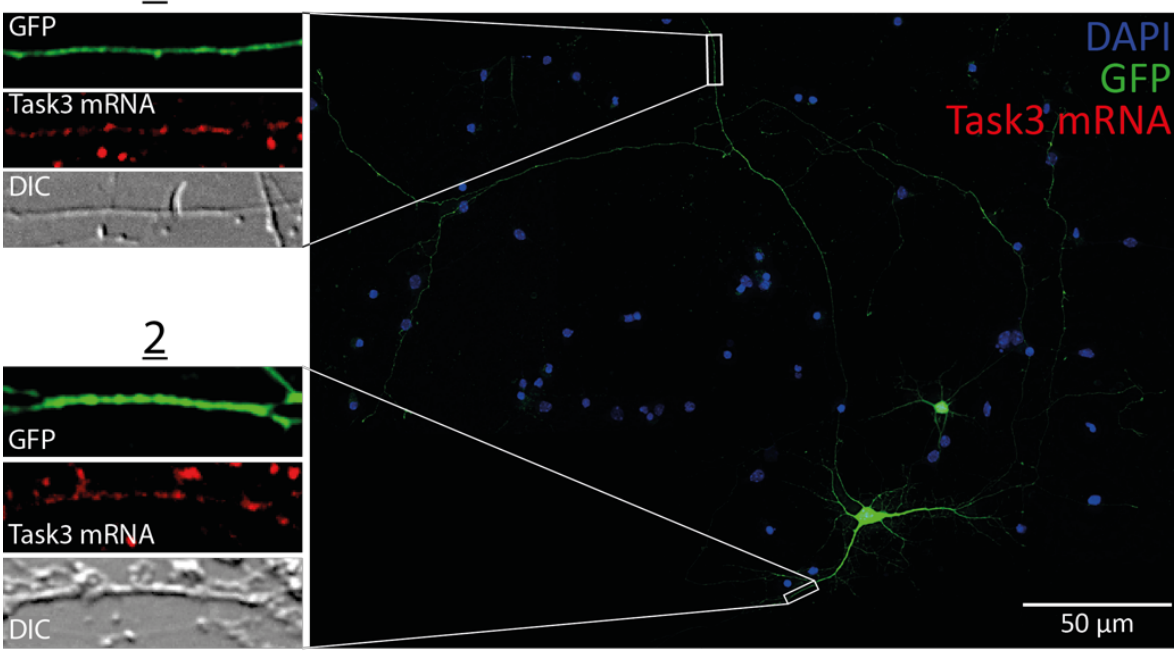

B

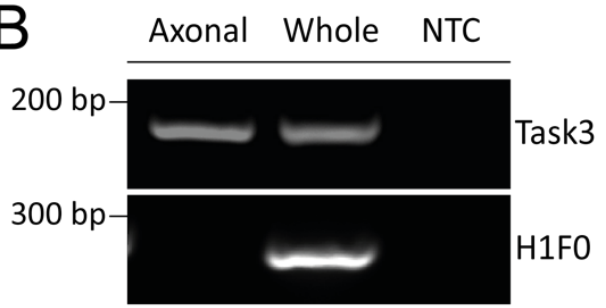

$400 \mathrm{bp}$

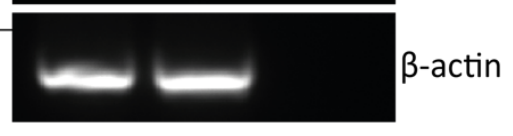

$\mathrm{MW}$

(kDa) Axonal Whole

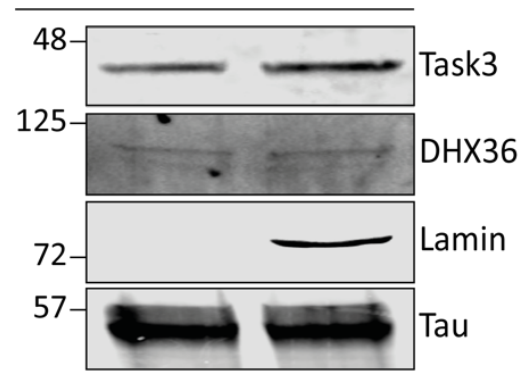

C

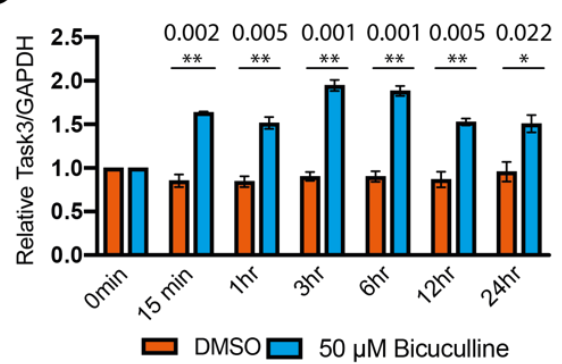

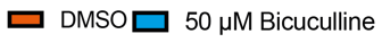

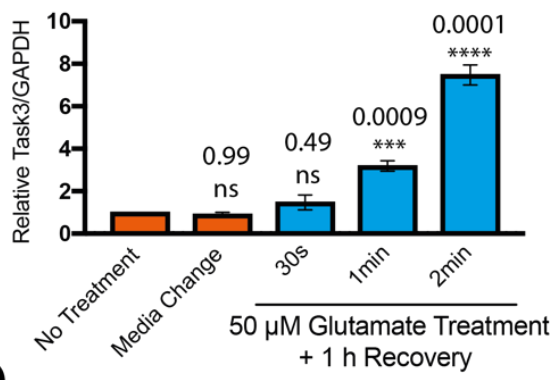

D

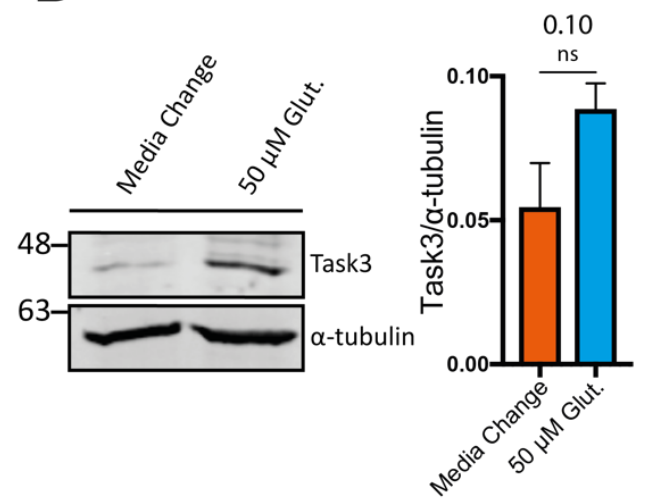

Figure 6 - Endogenous Task3 mRNA is localised to distal neurites and upregulates in response to neuronal activity - (A) RNA Fluorescence in situ Hybridisation (FISH) of eGFP transfected DIV10 embryonic murine cortical neurons hybridised with anti-Task3 mouse probes showing endogenous Task3 mRNA from a singular GFP transfected neuron in distal neurites. (B) Primary embryonic cortical neurons were cultured in Corning ${ }^{\circledR}$ Transwell $^{\circledR}$ inserts for the isolation of whole neuron vs axonal mRNA and protein. Western blot (left) and PCR (right) analyses were carried out from whole neuron vs axon protein and mRNA isolates. NTC $=$ no transcript control. (C) Total Task3 mRNA levels from DIV10 embryonic cortical neurons treated with $50 \mu \mathrm{M}$ bicuculline or DMSO over a $24 \mathrm{~h}$ period (top), as well as with $50 \mu \mathrm{M}$ glutamate for $30 \mathrm{~s}, 1 \mathrm{~min}, 2 \mathrm{~min}$ or a no-treatment control media change with a $1 \mathrm{~h}$ recovery period (bottom). (D) Western blotting of whole cortical cell lysates after 2 minutes treatment with $50 \mu \mathrm{M}$ glutamate or no-treatment control media change with a $1 \mathrm{~h}$ recovery period (Left) with quantification of endogenous Task3 expression normalised to $\alpha$-tubulin (Right). $\mathrm{N}=3$ biological replicates where error bars represent SEM. Statistical analyses were carried out by unpaired one-tailed T-tests or by one-way ANOVA $(F(4,10)=90.60, p<0.0001)$ with post-hoc Sidak's multiple comparison tests, p-values shown. 


\section{SUPPLEMENTARY DATA}

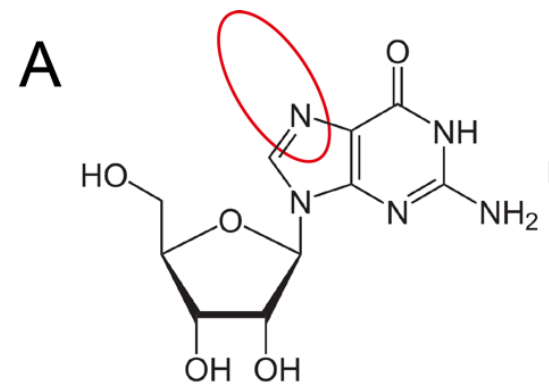

Guanosine

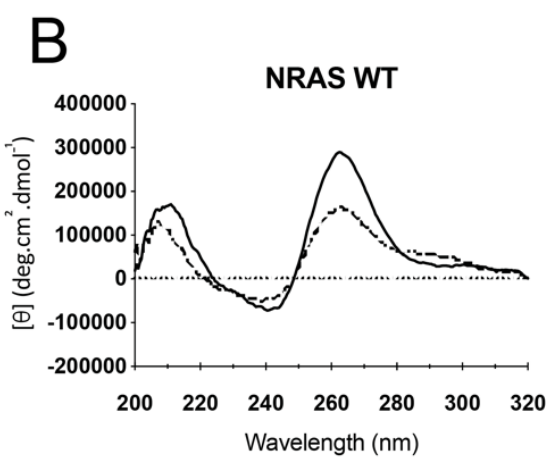

$\mathrm{D}$

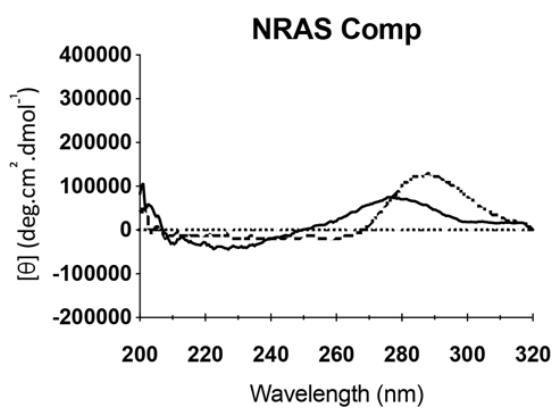

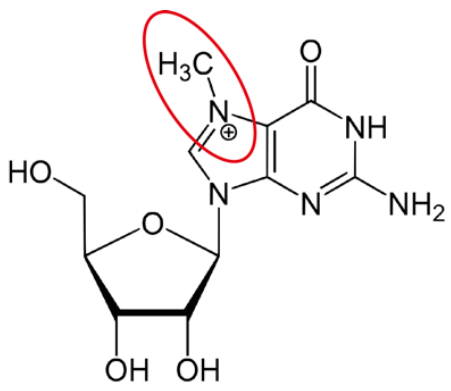

N7-Methylguanosine

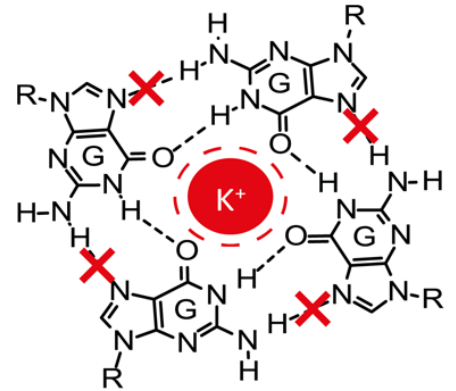

Task3 Comp

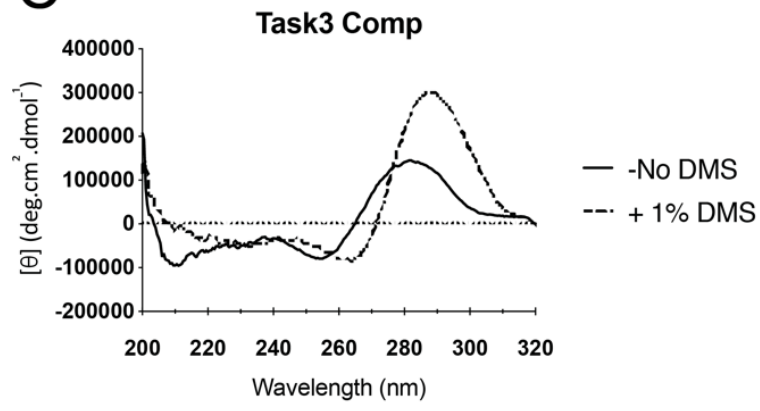

$E$

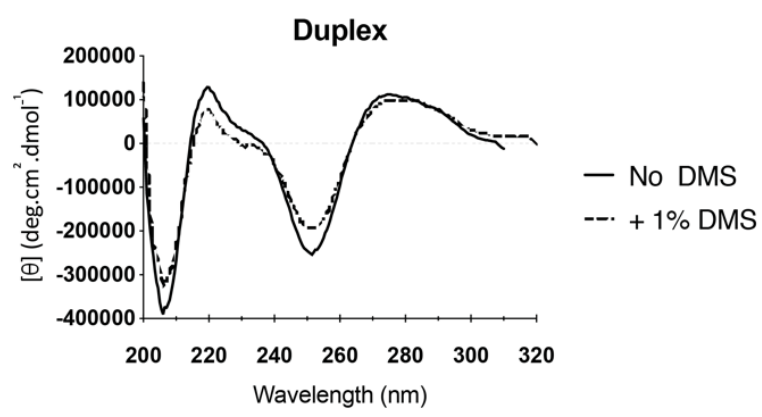

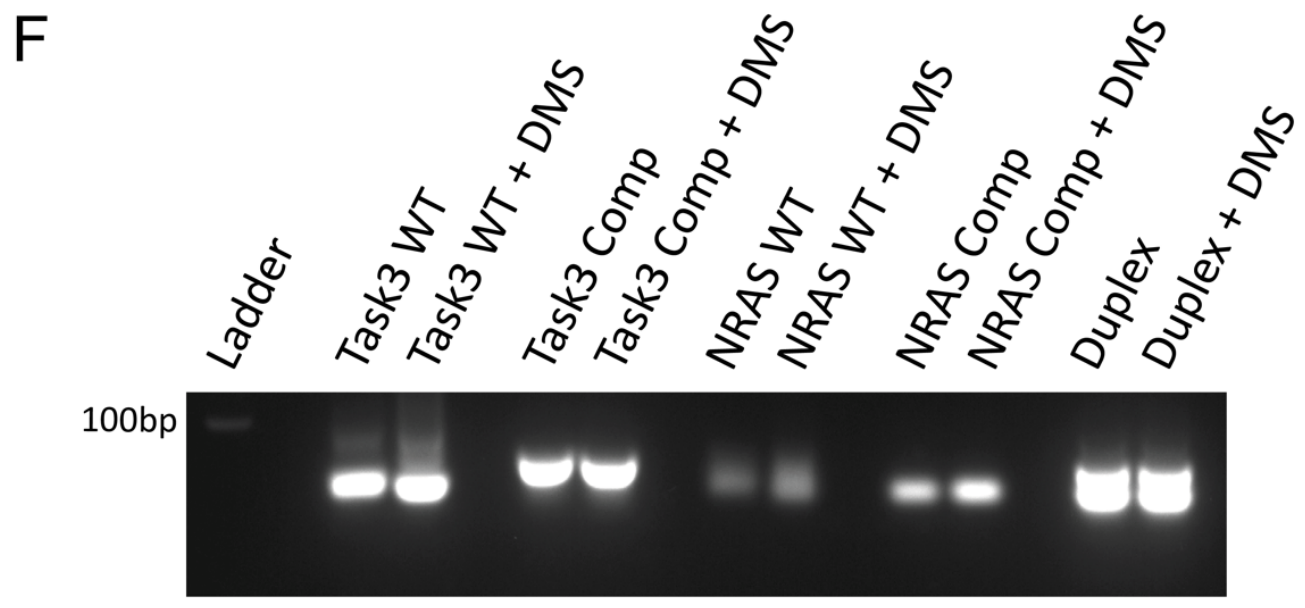

Figure S1 - 1\% DMS treatment inhibits G4 formation for Task3 WT (GGN) 13 and NRAS WT G4 - (A) Schematic showing the basis of DMS induced N7-methylation of guanine, inhibiting the Hoogsteen hydrogen bonding underpinning G-quartet formation. (B) CD spectra for NRAS WT G4 at $150 \mathrm{mM} \mathrm{K}^{+}$either in the presence of absence of $1 \%$ DMS pre-folding. (C) CD spectra for Task3 Comp (CCN) 13 at $150 \mathrm{mM} \mathrm{K}^{+}$either in the presence of absence of $1 \%$ DMS pre-folding. (D) CD spectra for NRAS Comp at $150 \mathrm{mM} \mathrm{K}^{+}$either in the presence of absence of $1 \%$ DMS pre-folding. (E) CD spectra for the duplex control at $150 \mathrm{mM} \mathrm{K}^{+}$either in the presence of absence of $1 \%$ DMS prefolding. (F) All aforementioned samples run on $1 \%$ agarose gel post-CD analysis. CD spectra were obtained from five repeated acquisitions to increase the signal:noise ratio with a representative trace shown. 

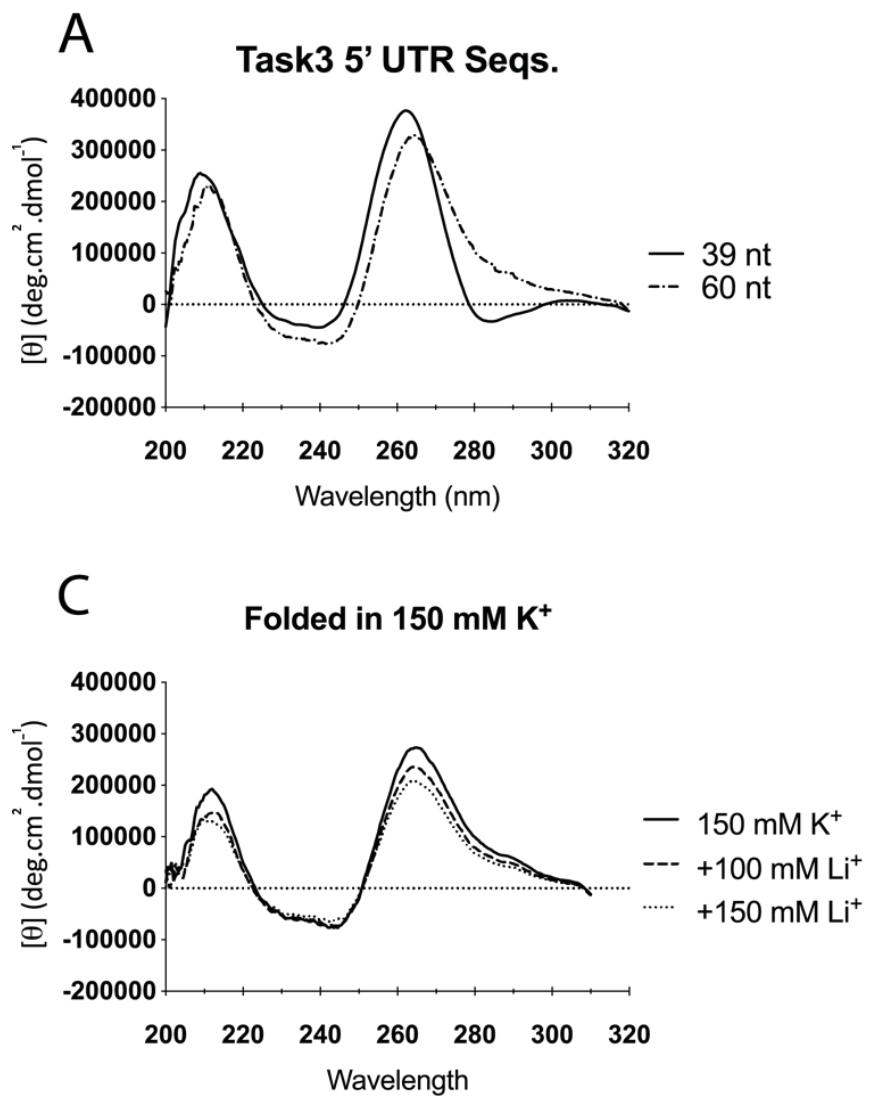
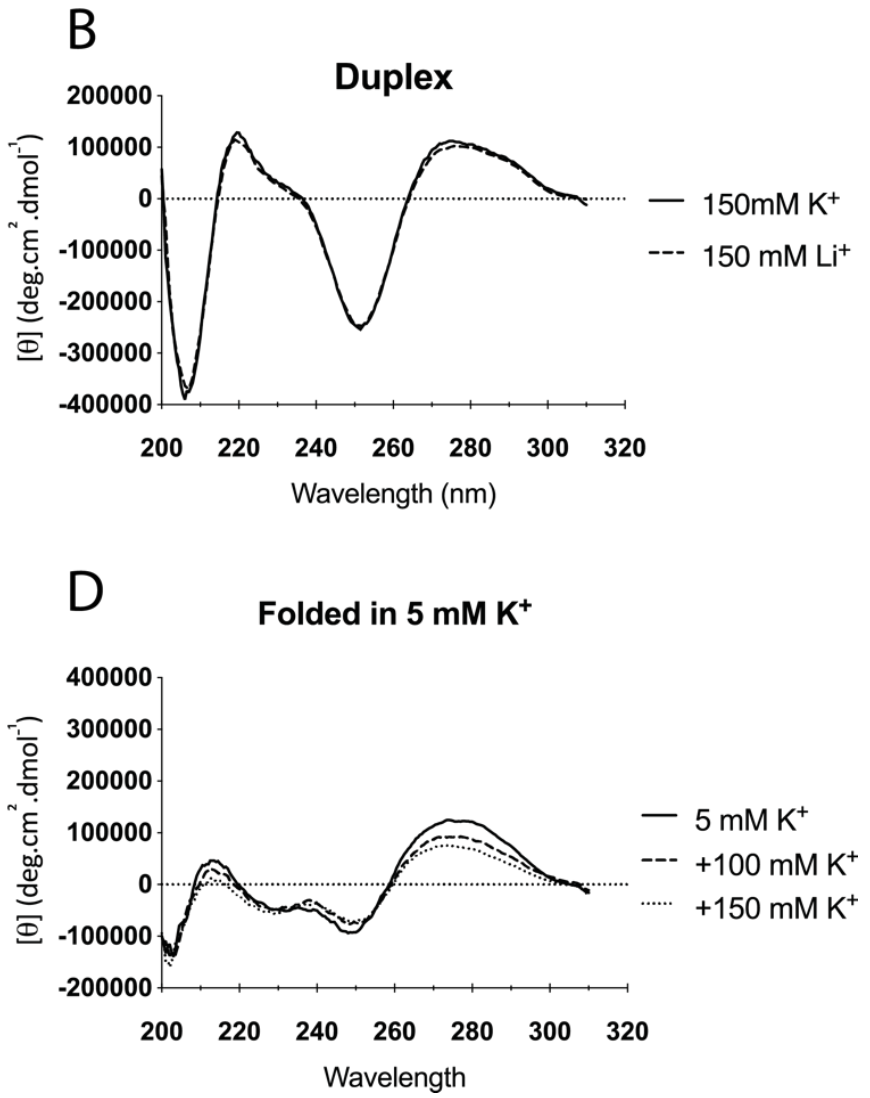

Figure S2 - Further characterisation of oligonucleotides via circular dichroism - (A) The CD spectra of $10 \mu \mathrm{M}$ oligos containing either the Task3 WT (GGN) 13 repeat or a longer $60 \mathrm{nt}$ sequence containing the WT (GGN) 13 repeat with the $11 \mathrm{nt}$ upstream and $10 \mathrm{nt}$ downstream found within Task3 5' UTR, folded in potassium phosphate buffer supplemented with $\mathrm{KCl}$ to $150 \mathrm{mM} \mathrm{K}^{+}$. (B) he $\mathrm{CD}$ spectra of $10 \mu \mathrm{M}$ duplex forming oligos folded in potassium phosphate buffer supplemented with $\mathrm{KCl}$ to $150 \mathrm{mM} \mathrm{K}^{+}$or folded in sodium phosphate supplemented with $\mathrm{LiCl}$ to $150 \mathrm{mM} \mathrm{Li}{ }^{+}$. (C) The CD spectra for Task3 WT (GGN)13 pre-folded in potassium phosphate buffer supplemented with $\mathrm{KCl}$ to $150 \mathrm{mM} \mathrm{K}^{+}$and subsequently supplemented with 100 - and $150 \mathrm{mM} \mathrm{LiCl}$ thereafter. (D) The CD spectra for Task3 WT (GGN) ${ }_{13}$ pre-folded in potassium phosphate buffer supplemented with $\mathrm{KCl}$ to $5 \mathrm{mM} \mathrm{K}^{+}$and subsequently supplemented with $100-$ and $150 \mathrm{mM} \mathrm{KCl}$ thereafter. CD spectra were obtained from five repeated acquisitions to increase the signal:noise ratio with a representative trace shown. 
A

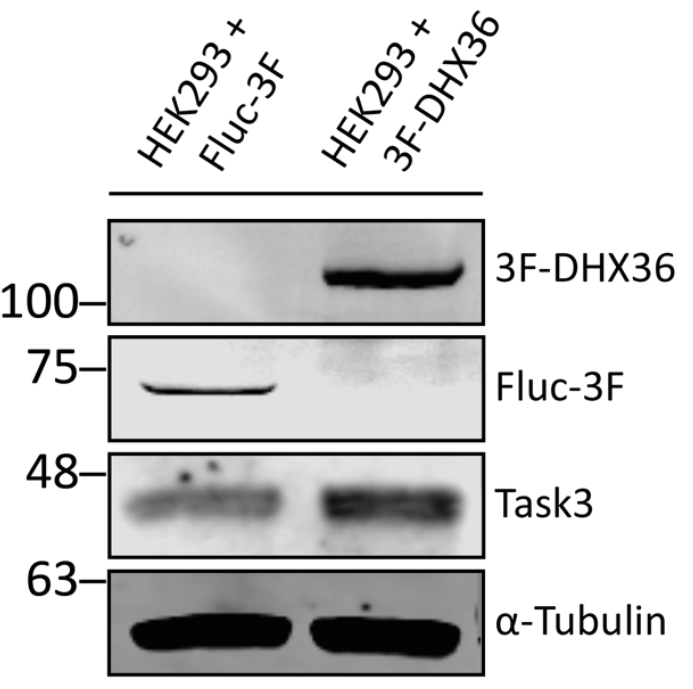

B

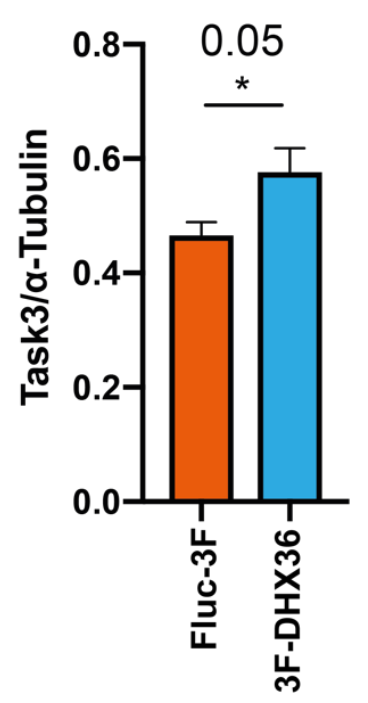

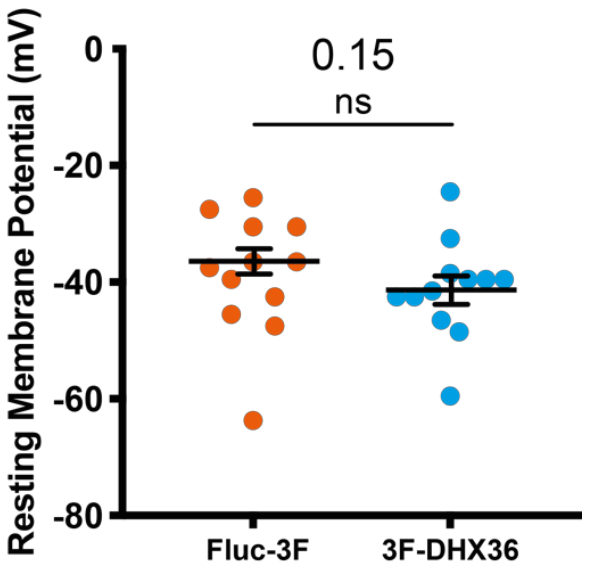

Figure S3 - Overexpression of DHX36 increases translation of endogenous Task3 - (A) Western blotting of HEK293 lysates transfected with Fluc-3F or 3F-DHX36 (Left) and quantified for endogenous Task3 expression (Right). (B) Whole cell patch clamp recordings of HEK293 cells transfected with Fluc-3F or 3F-DHX36. N=3 biological replicates where error bars represent SEM. Statistical analyses were carried out by unpaired one-tailed T-tests, $p$ values shown.

A

Figure S4 - RNA FISH of Task3 ${ }^{\mathrm{M} 1}$-eGFP in DIV10 primary cortical neurons at a short exposure to define mRNA granules within the cell body (A), and at a long exposure to define mRNA granules in the neurite projections (B). 
FLAG (F: 5'-ACTACAAAGACCATGACGGTG-3', R: 5'-TCGTCATCCTTGTAGTCGATGTC-3'),

$\beta_{2} \mathbf{M}$ (F: 5'-TTCATCCATCCGACATTGAAG-3', R: 5'-ATCCAATCCAAATGCGGC-3'),

NPTII (F: 5'-CTCACCTTGCTCCTGCCGAGA-3', R: 5'-CGCCTTGAGCCTGGCGAACAG-3'),

GAPDH (5'-TGAACGGGAAGCTCACTGG-3', R: 5'-TCCACCACCCTGTTGCTGTA-3'),

Task3 (5'-CACAACTATCGGATATGGAC-3', R: 5'-CTCCATAGAAACTTCAGTGTTG-3'),

DHX36 (5'-ATGGATGAACGTCGAGAAGAGC-3', R: 5'- ATACCCATGATCCTCAGGAGC-3'),

$\beta$-Actin (5'-CAGCCTTCCTTCTTGGGTATG-3', R: 5'-AGCTCAGTAACAGTCCGCCT-3'),

H1F0 (5'-CCATCGGAAGGCTCCTTGAA-3', R: 5'-CACTAGGCGCTTGATGGACA-3').

Task3 RACE GSP: (R: 5'- AACGTGCGGACTCTGTCC -3').

Figure S5 - List of primers used for PCR and qPCR obtained from Sigma. 